May 2015

"On the Political Economy of University Admission Standards"

Philippe DE DONDER, Francisco MARTINEZ-MORA 


\title{
On the Political Economy of University Admission Standards ${ }^{1}$
}

\author{
Philippe De Donder ${ }^{2} \quad$ Francisco Martinez-Mora ${ }^{3}$
}

May 22, 2015

\footnotetext{
${ }^{1}$ We thank Antonio Cabrales, Bernardo Moreno, Richard Romano and audiences at Aixen-Provence (AMSE), Montréal (UQAM), Québec (U Laval), Yale and the 2014 PET meeting (Seattle) for their comments. Part of this research has been done while the first author was visiting UQAM (Montréal), whose hospitality is gratefully acknowledged.

${ }^{2}$ Corresponding author. Toulouse School of Economics (CNRS-GREMAQ and IDEI). Email: philippe.dedonder@tse-fr.eu

${ }^{3}$ University of Leicester, Universitat Rovira i Virgili \& CREIP. Email: fmm14@leicester.ac.uk
} 


\begin{abstract}
We study the political determination of the proportion of students attending university when access to higher education is rationed by admission tests. Parents differ in income and in the ability of their unique child. They vote over the minimum ability level required to attend public universities, which are tuition-free and financed by proportional income taxation. University graduates become high skilled, while the other children attend vocational school and become low skilled. Even though individual preferences are neither single-peaked nor single-crossing, we obtain a unique majority voting equilibrium, which can be either classical (with $50 \%$ of the population attending university) or "ends-againstthe-middle", with less than $50 \%$ attending university (and parents of low and high ability children favoring a smaller university system). The majority chosen university size is smaller than the Pareto efficient level in an ends-against-the-middle equilibrium. Higher income inequality decreases the majority chosen size of the university. A larger positive correlation between parents' income and child's ability leads to a larger university populated by a larger fraction of rich students, in line with the so-called participation gap. Our results are robust to the introduction of private schooling alternatives, financed with fees.
\end{abstract}

JEL codes: D72, I22

Keywords: majority voting, ends-against-the-middle, non single-peaked preferences, non single-crossing preferences, higher education participation gap, income ability correlation, size of university 


\section{Introduction}

In many countries across the globe, the public sector offers tuition-free higher education financed through general taxation. This is the case in a large number of European and Latin American countries, as well as in two of the BRIC countries (Brazil and India). According to Eurydice (2013) and OECD (2013), Austria, Cyprus, the Czech Republic, Denmark, Finland, Greece, Iceland, Malta, Norway, Poland, Scotland, Slovakia, Slovenia, Sweden, and Germany charged higher education students no tuition fees or extremely low administrative fees in the academic year 2012/2013. In other countries such as Belgium, Bulgaria, Croatia, France, Italy, Liechtenstein, Montenegro, Portugal, Spain and Turkey, fees were below or very close to $€ 1,000$ per year. ${ }^{1}$ Moreover, in these countries, youths from underprivileged backgrounds are usually eligible for generous grant programs. Rather than by fees, access to university education is rationed by some measure of academic ability -i.e., access is limited to students who demonstrate some minimum ability level. ${ }^{2}$

In this paper, we study the political determination of higher education admission standards- i.e., of the minimum ability level required to access higher education. This threshold ability level in turn determines the fraction of the population receiving a university education and becoming highly skilled. We are therefore interested in the political determination of the proportion of skilled and unskilled workers in the economy, when access to higher education is rationed by admission tests.

Figure 1 reports both the enrolment rate (full-time and part-time students in public and private institutions) among 20 to 29 year old students and the proportion of 25 to 64 years old who have obtained a tertiary degree, for the European countries listed above, in

\footnotetext{
${ }^{1}$ This was also true of the UK from the 1960s until 1997, and of China and Russia until the 1990s. Within Latin America, Argentina, Brazil, Cuba, Ecuador, Mexico, Venezuela and Uruguay currently provide tuition-free university education to domestic students, while the Chilean government recently announced that their country will join this group by 2016. Worldwide, close to two billion people currently live in countries with tuition-free public universities. See OECD (2013) and Carnoy et al. (2013).

${ }^{2}$ The test verifying that a minimum ability is attained may take the form of a university admission test (as in Spain or the UK), or may be merged with the exam taken at the end of secondary education (as in Belgium and France, for instance).
} 
$2010 .^{3}$ A striking feature of this figure is that, notwithstanding the heterogeneity across countries, both measures depicted are strictly lower than one half for all countries.

\section{Insert Figure 1 around here}

Our aim in this paper is to build a simple political economy model where the minimum ability level of higher education students is determined through majority voting, ${ }^{4}$ to investigate the characteristics of the majority voting equilibrium, and to study how it is affected by factors such as the degree of income inequality, the correlation between income of the parents and the academic ability of the children, the availability of private schooling alternatives or the labor market wage premium for higher education graduates.

We assume that parents differ in income and in the academic ability of their unique child. Children whose ability is below a threshold level attend a costless vocational program and become low-skilled, while those whose ability is at least equal to the threshold attend university and become high-skilled. University is financed with an income tax on the whole (parents) population. The future wage earned by students is the product of their ability and of the reference wage of their skill level. The skill premium (difference in reference wage across skill levels) depends on the relative supply of each type of labor, and is thus a function of the ability threshold democratically chosen. ${ }^{5}$ Parents care for their child's future wage and vote over the minimum ability level giving access to higher education.

We first show that parents of low ability children most-prefer a minimum ability level at university that leaves their child unskilled, while parents of high ability children most prefer a minimum ability level compatible with their child attending university. The

\footnotetext{
${ }^{3}$ The source for Figure 1 is OECD (2012), Table A1.4. and Table C1.1a., respectively.

${ }^{4}$ Voting is the most natural way to endogenize the fraction of students attending public universities in democracies.

${ }^{5}$ This assumption accords well with basic intuition and with state-of-the-art models of the labor market (e.g. Acemoglu, 2003; Acemoglu and Autor, 2011; Carneiro and Lee, 2011).
} 
intuition runs as follows. For their child to attend university (and enjoy the larger highskilled wage), parents have to set the minimum ability threshold at most equal to their child's ability level. This can prove very costly for parents of a low ability child (because of the tax cost of a large university system), and for rich parents (who bear a larger share of the burden of financing public universities). Such parents then most prefer their child to become low-skilled. Note that this does not entail that they oppose any positive university size, because they want to restrict the supply of low skill agents to boost their child's wage.

The voting problem we consider has an inherent theoretical interest, since individual preferences are neither single-peaked in the minimum ability level at university nor singlecrossing (à la Gans and Smart 1996), because of the switch to vocational schooling when that level becomes larger than the child's ability. We nevertheless prove the existence of a unique majority voting equilibrium (a Condorcet winning value of the minimum ability required to access university), which can be either "classical" (where parents with children in the bottom half -resp., top half- of the ability distribution prefer a larger -resp., smaller-- university size) or "ends-against-the-middle" à la Epple and Romano (1996) (where parents of both low and high ability children prefer a smaller university size, in opposition to parents of middle ability kids) ${ }^{6}{ }^{6}$ While the equilibrium size of the public university is $50 \%$ of the student population in the "classical" equilibrium, it is strictly less than $50 \%$ in the other equilibrium. The ends-against-the-middle equilibrium is then in line with Figure 1, while the $50 \%$ participation rate in higher education in the classical equilibrium corresponds to targets announced during electoral campaigns by Tony Blair in 2001 for the UK, and by François Hollande in 2012 for France.

Focusing on the ends-against-the-middle equilibrium, we obtain that the equilibrium university size is too small, compared to its Pareto efficient level. The decisive voter's child does not attend university, so that the voter's preferred university size balances the tax benefit of a smaller university with the resulting lower vocational wage for his child.

\footnotetext{
${ }^{6}$ After completing this research, Bernardo Moreno has pointed out to our attention that individual preferences in our setting satisfy the top monotonicity requirement: see Barberá and Moreno (2011).
} 
The decisive voter then does not take into account another social cost of decreasing the university size, which is to decrease the wage of the marginal agents whose access to university is barred.

Turning to the comparative statics analysis of majority voting equilibrium, we find four factors which unambiguously decrease the university size, both by making the endsagainst-the-middle equilibrium more likely and by decreasing the university size in that equilibrium: a more costly university system, a smaller degree of altruism of parents, a vocational wage less sensitive to the supply of low skilled workers, and a larger income inequality (modelled as a means-preserving spread of the income distribution). An increase in the fraction of poor parents makes the ends-against-the-middle equilibrium more likely, but has an ambiguous effect on the equilibrium size of the university in that case.

Results obtained so far assume away any correlation between parent's income and child's ability. Lifting this assumption, we obtain that a larger positive correlation increases both the majority chosen university size in an ends-against-the-middle equilibrium and the fraction of university students with rich parents. We obtain this result both analytically with two income levels, and numerically in a more general environment with, among others, a continuum of parental income levels. This result provides a potential explanation to the puzzling experience of many countries since the end of World War II, where a dramatic expansion of higher education has not closed the so-called "participation gap", defined as the difference in higher education participation rates between rich and poor students. ${ }^{7}$ Observe that we take the correlation between income and ability as a datum of our problem. We come back to this point in the concluding section.

Finally, we show throughout the paper that our results are robust to the introduction of several natural extensions, such as a continuum of parental income levels, parent's utility concave in their own consumption, uncertainty as to the future income of the child, costly

\footnotetext{
${ }^{7}$ There is a growing empirical literature that provides evidence on this process for different countries. See among others Blanden and Machin (2004) and Galindo-Rueda et al. (2004) for the UK, Bratti et al. (2008) for Italy, Carnoy et al. (2012) for the BRIC countries, Rahona-López (2009) for Spain and Vona (2012) for 12 European countries.
} 
vocational schools, non-proportional taxation, university peers effects, an endogenous high skilled reference wage, and private schooling alternatives (financed exclusively by attendance fees), both at the vocational and university levels.

Our paper belongs to a relatively small but growing literature studying access conditions to higher education, together with its financing. Most contributions focus on the impact of fees and on various subsidization policies. Fernández and Rogerson (1995) assume that citizens vote over the size of a tax-financed subsidy and obtain that the political equilibrium subsidy level is not large enough to allow poor students to access higher education, resulting in redistribution from the poor to the rich. Building upon this observation, Garcia-Peñalosa and Wälde (2000) compare the efficiency and equity effects of a traditional tax-subsidy scheme, a graduate tax and loans, and obtain that the latter two fare better than the former. Moreover, when education outcomes are uncertain, the graduate tax is to be preferred. Haupt (2012) extends the political economy analysis of the traditional tax-subsidy scheme to a dynamic setting and shows that high and low levels of public spending in higher education may alternate in a democracy. Del Rey and Racionero $(2012,2014)$ focus their attention on the political economy and the efficiency and equity properties of income-contingent loans. Borck and Wimbersky (2014) study numerically majority voting over a traditional subsidy scheme, a pure loan scheme, income contingent loans and graduate taxes by risk averse households who are heterogeneous in income. Surprisingly, they find that the poor favor the subsidy scheme, even though they pay part of its tax cost. ${ }^{8}$

Two papers study admission tests either together with, or instead of, (subsidized) tuition fees: Gary-Bobo and Trannoy (2008) study the socially optimal examinationcum-fees policy. They assume that students observe only a private, noisy signal of their ability, and that universities can condition admission decisions on the results of noisy tests. Tests are part of the optimal policy provided that their results are not public knowledge.

\footnotetext{
${ }^{8}$ Other important contributions in the area (e.g. Epple et al. 2006; De Fraja and Valbonesi, 2012; Romano and Tampieri, 2013; or Fu, 2014) are less closely related to this paper.
} 
The paper most closely related to ours is De Fraja (2001). As in our model, parents differ in income and in the ability of their child and face a binary educational choice but, unlike here, universities charge fees to students, and the future income of children is random and determined only by their own education decision. An important consequence of these assumptions is that better-off children are more likely to attend university than poorer ones in a laissez-faire equilibrium. This is not the result of credit constraints (assumed away) but of the risk involved in an investment in higher education: preferences satisfy decreasing absolute risk aversion and so better-off parents are more willing to bear the risk. The market allocation then fails to provide equality of opportunity and to reach production efficiency. De Fraja (2001) then studies two forms of intervention, exclusive of each other: an admission test similar to ours, and a subsidy financed by proportional income taxation. In both cases, he analyzes the majority voting equilibrium and shows that both policies enhance equality of opportunity, but that their equity and efficiency effects are ambiguous. Preferences for the admission test are simpler than in our model because parents whose children do not attend university are indifferent as to its size (since they do not finance university education through taxes, and the future income of an unskilled agent is not affected by the proportion of university graduates), allowing for the direct application of the median voter theorem. Our paper can then be seen as an extension of De Fraja (2001) in three dimensions: (i) the decision to attend university by an additional agent exerts an externality on the rest, by raising low-skilled wages and lowering the skill premium, (ii) we study majority voting over the admission test level in the presence of (full) subsidy of fees, and (iii) we allow for the existence of private alternatives to public education. We find these extensions important because labor market effects are a crucial aspect of the problem, because many countries do not use fees to ration access to university, as we argued above, and because interactions between public and private educational options have proved essential in similar contexts (e.g. Epple and Romano, 1996).

The remainder of the paper is organized as follows: after presenting the model in section 2, we describe households' preferences over the admission ability threshold in 
section 3. Existence of a majority voting equilibrium is studied in section 4 . The outcome of the voting process is then compared to the efficient admission threshold in section 5 . Section 6 provides a comparative statics analysis of the majority chosen university size, while section 7 shows that our results are robust to the introduction of private schooling alternatives. Section 8 concludes.

\section{The model}

We model a static economy, with a continuum of individuals (parents) of mass one. Parents differ in their (exogenous) income $w$ which can take two values: $w_{L}$ and $w_{H}$ with $w_{L}<w_{H}$. A fraction $\lambda$ has low income, so that average income is $\bar{w}=\lambda w_{L}+(1-\lambda) w_{H} \cdot{ }^{9}$ Each parent has one child of a given (and known) ability degree $\theta$. Abilities are distributed over $] 0, \bar{\theta}]$ according to the $\operatorname{CDF} F($.$) and density f($.$) . While the smallest conceivable$ ability may tend toward zero, the smallest ability level actually observed in the economy is $\underline{\theta}$, and the density has full support over $[\underline{\theta}, \bar{\theta}]$. The median value of $\theta$ is denoted by $\theta_{\text {med }}$. With a slight abuse of language, we denote by $(\theta, i)$ with $i \in\{L, H\}$ the type of the parent. Except in the second part of section 6, we assume no correlation between parent's income and child's ability, so that the distribution of ability is the same whether $i=L$ or $H$.

The (binary) skill level $j$ of children is determined by education. Children who go to a vocational school $(j=V)$ become low-skilled, while those who go to university $(j=u)$ become high-skilled. We denote by $\theta_{u}$ the minimum level of ability required to be admitted to a university and to become high-skilled. After completing school, children work and obtain a wage which is the product of their idiosyncratic ability, $\theta$, and of the reference

\footnotetext{
${ }^{9}$ Our framework generalizes to a continuum of income levels on the interval $\left[w_{L}, w_{H}\right]$. More precisely, we obtain exactly the same type of equilibrium with a continuum of income levels as with two income levels, and all results reported in sections 3 and 4 would hold with a continuum of income levels. Having just two income levels simplifies the notation and allows to obtain unambiguous analytical comparative statics analysis when modifying the income distribution (see Proposition 4). We provide at the end of section 6 numerical results with a continuum of income levels.
} 
wage for their skill level, $\omega_{j} .{ }^{10}$ The skill premium $\omega_{u}-\omega_{V}$ is increasing (resp., decreasing) in the fraction of low-skilled (resp., high-skilled) agents, and is always strictly positive. To simplify the algebra (and without loss of generality for our results), we assume that the skilled reference wage $\omega_{u}$ is exogenous (for instance, set by the world market). At the same time, $\omega_{V}$ decreases with the proportion of low-skill agents. As we will see shortly, all children bright enough to be accepted at the university (i.e., with $\theta>\theta_{u}$ ) indeed attend university and become high-skilled, so that the proportion of low-skill agents is $F\left(\theta_{u}\right)$. To save on notation, we will often use the shortcut $\omega_{V}\left(\theta_{u}\right)$ rather than $\left.\omega_{V}\left(F\left(\theta_{u}\right)\right)\right)$. Note then that $\omega_{V}^{\prime}\left(\theta_{u}\right)=\left(\partial \omega_{V}\left(F\left(\theta_{u}\right)\right) / \partial F\right) f\left(\theta_{u}\right)<0$. Observe that, although the individual wage $\theta \omega_{V}\left(\theta_{u}\right)$ of low-skilled agents is decreasing in $\theta_{u},{ }^{11}$ their average wage,

$$
\frac{1}{F\left(\theta_{u}\right)} \int_{\underline{\theta}}^{\theta_{u}} \theta \omega_{V}\left(\theta_{u}\right) d F(\theta),
$$

may be increasing in $\theta_{u}$ by a composition effect, since their average ability increases with the threshold $\theta_{u}$.

The cost of vocational education is normalized to zero, while universities are costly: the (constant) cost per student of university education is $c_{u}$, and is financed through a proportional tax on income at rate $t$, paid by all parents. ${ }^{12}$ The government budget constraint is then

$$
t \bar{w}=c_{u}\left(1-F\left(\theta_{u}\right)\right) .
$$

\footnotetext{
${ }^{10}$ So, even though there are only two skill levels, the actual income of workers of a given skill level is continuously increasing in their ability. All results in this paper can be generalized to a setting with uncertainty (as to the probability of actually graduating or the future wage amount) as long as the expected wage of students increases with $\theta$ (for instance because of a lower dropout rate) and is larger when attending university rather than the vocational school, whatever $\theta$.

${ }^{11}$ One could argue that the sensitivity of wages to the own productivity parameter should be weaker for unskilled workers than for skilled ones. Our results are robust to this possibility, with unskilled wages given by $\theta^{\alpha} \omega_{V}\left(\theta_{u}\right)$, provided that $0<\alpha \leq 1$. See footnote 17 for the impact of $\alpha=0$.

${ }^{12}$ Since all children get some form of education in our model, adding a cost for vocational education would not change our results provided we interpret $c_{u}$ as the difference between the per student university and vocational school costs. Also, the assumption of proportional taxation is made for simplicity only, with all our results continuing to hold provided that taxes paid increase with income.
} 
Parents care both about their own consumption (after-tax income) and about the future wage of their kid. If their child becomes highly skilled, the parent's utility is

$$
U_{u}\left(\theta_{u}, w_{i}, \theta\right)=w_{i}\left(1-t\left(\theta_{u}\right)\right)+\delta \theta \omega_{u}
$$

while it is

$$
U_{V}\left(\theta_{u}, w_{i}, \theta\right)=w_{i}\left(1-t\left(\theta_{u}\right)\right)+\delta \theta \omega_{V}\left(\theta_{u}\right)
$$

if the child remains low-skilled. ${ }^{13}$ The parameter $\delta>0$ measures the intensity of the altruism of parents towards their child.

The timing of the model is as follows. Parents first vote over the threshold $\theta_{u}$. They then decide individually whether to enrol their unique child at university. Solving the second stage is straightforward: since the skill premium is always positive, i.e. $\omega_{u}>$ $\omega_{V}\left(\theta_{u}\right) \forall \theta_{u}$, we have that $U_{u}\left(\theta_{u}, w_{i}, \theta\right)>U_{V}\left(\theta_{u}, w_{i}, \theta\right)$ for all $\theta$ : parents pay the same tax in both cases (since the university has the same size), but their child has a larger income when high skilled than when low skilled. All parents with $\theta \geq \theta_{u}$ thus enrol their child at university.

We next look at parents' preferences over the threshold level $\theta_{u}$ before aggregating these preferences through majority voting.

\section{Individual preferences over $\theta_{u}$}

We proceed in two steps. We first look at individuals' preferences over $\theta_{u}$ as a function of the (exogenous) type of education received by the child (university or vocational), and we then look at overall preferences over $\theta_{u}$ when the education type is determined by whether the child's ability reaches the threshold $\theta_{u}$ or not.

\footnotetext{
${ }^{13}$ The assumption that utility is linear in consumption is made for simplicity only. Our results generalize to any setting with concave utility for own consumption, provided that the degree of relative risk aversion is everywhere either lower than one or greater than one. In the latter case, the roles played by low and high income are interchanged in the analysis - the proof is available upon request to the authors. We provide numerical results where utility is concave in current consumption at the end of section 6 .
} 
We start with the preferences over $\theta_{u}$ of parents whose children attend a university:

$$
\frac{\partial U_{u}\left(\theta_{u}, w_{i}, \theta\right)}{\partial \theta_{u}}=-w_{i} t^{\prime}\left(\theta_{u}\right)>0
$$

since

$$
t^{\prime}\left(\theta_{u}\right)=-\frac{c_{u} f\left(\theta_{u}\right)}{\bar{w}}<0
$$

Conditional on their child going to university, parents always most-prefer a smaller university size (i.e., larger $\theta_{u}$ ) since it decreases their tax bill without affecting the exogenous reference wage received by high-skilled agents. ${ }^{14}$

Alternatively, the most-preferred value of $\theta_{u}$ of a parent whose child remains lowskilled, which we denote by $\theta_{u}^{*}\left(w_{i}, \theta\right)$, satisfies the following FOC:

$$
\delta \theta \frac{\partial \omega_{V}\left(F\left(\theta_{u}^{*}\right)\right)}{\partial F}=-c_{u} \frac{w_{i}}{\bar{w}}
$$

This individually optimal size trades off the smaller vocational wage associated to a smaller university (the left-hand side of (4)) with the smaller tax bill (the right-hand side of (4)). The necessary and sufficient condition for the SOC

$$
\delta \theta \frac{\partial^{2} \omega_{V}\left(F\left(\theta_{u}\right)\right)}{\partial F^{2}} f\left(\theta_{u}\right)<0
$$

to be satisfied is that $\partial^{2} \omega_{V}\left(F\left(\theta_{u}\right)\right) / \partial F^{2}<0$. We assume from now on that the SOC holds and that $\underline{\theta}<\theta_{u}^{*}\left(w_{i}, \theta\right)<\bar{\theta}$ for all $(\theta, i)$.

The following lemma performs the comparative statics analysis of $\theta_{u}^{*}$.

Lemma $1 \theta_{u}^{*}\left(w_{i}, \theta\right)$ decreases with $\theta$ and $\delta$ and $\theta_{u}^{*}\left(w_{L}, \theta\right)<\theta_{u}^{*}\left(w_{H}, \theta\right)$.

Proof. Applying the implicit function theorem on the FOC (4), and assuming an interior solution, we obtain that ${ }^{15}$

$$
\begin{aligned}
\frac{\partial \theta_{u}^{*}\left(w_{i}, \theta\right)}{\partial w_{i}} \stackrel{s}{=}-t^{\prime}\left(\theta_{u}\right) & >0, \\
\frac{\partial \theta_{u}^{*}\left(w_{i}, \theta\right)}{\partial \delta} \stackrel{s}{=} \theta \frac{\partial \omega_{V}\left(F\left(\theta_{u}\right)\right)}{\partial F} & <0, \\
\frac{\partial \theta_{u}^{*}\left(w_{i}, \theta\right)}{\partial \theta} \stackrel{s}{=} \delta \frac{\partial \omega_{V}\left(F\left(\theta_{u}\right)\right)}{\partial F} & <0 .
\end{aligned}
$$

\footnotetext{
${ }^{14}$ Adding university peer effects would reinforce the attractiveness of a smaller (and more elitist) university. So would making $\omega_{u}$ endogenous and decreasing in the fraction of high skill workers.

${ }^{15}$ Observe that we keep $\bar{w}$ constant in (5) since our objective is to compare $\theta_{u}^{*}\left(w_{L}, \theta\right)$ and $\theta_{u}^{*}\left(w_{H}, \theta\right)$.
} 
Richer parents pay more taxes and are thus in favor of a smaller university when their child does not attend university. Also, parents of brighter low-skilled kids put more weight on the reference vocational wage (because their children wages increase with $\theta$ ) and thus favor a larger university to restrict the supply of low-skilled agents and to boost this reference wage. A similar phenomenon occurs for all parents when the degree of altruism is increased.

The following lemma will prove useful in several proofs.

Lemma 2 There exists a unique value of $\theta$ for each income level $i \in\{L, H\}$, denoted by $\hat{\theta}_{i}$, such that $\theta_{u}^{*}\left(w_{i}, \theta\right)>\theta$ for all $\theta<\hat{\theta}_{i}$ and $\theta_{u}^{*}\left(w_{i}, \theta\right)<\theta$ for all $\theta>\hat{\theta}_{i}$.

Proof. Observe that $\lim _{\theta \rightarrow 0} \theta_{u}^{*}\left(w_{i}, \theta\right)=\bar{\theta}>0, \theta_{u}^{*}\left(w_{i}, \bar{\theta}\right)<\bar{\theta}$ and $\partial \theta_{u}^{*}\left(w_{i}, \theta\right) / \partial \theta<0$.

We now study the preferences over $\theta_{u}$ when the child's educational track is endogenous. This means that a parent anticipates that his child will be low-skilled if $\theta_{u}>\theta$ and will attend university and become high-skilled if and only if $\theta_{u} \leq \theta$. His utility over $\theta_{u}$ is then given by

$$
\begin{aligned}
U\left(\theta_{u}, w_{i}, \theta\right) & =U_{u}\left(\theta_{u}, w_{i}, \theta\right) \text { if } \theta_{u} \leq \theta \\
& =U_{V}\left(\theta_{u}, w_{i}, \theta\right) \text { if } \theta_{u}>\theta
\end{aligned}
$$

Observe that there is a discontinuous decrease in utility for all agents at $\theta_{u}=\theta$, since the skill premium is positive and so $U_{u}\left(\theta_{u}, w_{i}, \theta\right)>U_{V}\left(\theta_{u}, w_{i}, \theta\right) \forall \theta, \theta_{u}$. It is straightforward to see that preferences are single-peaked in $\theta_{u}$ if $\theta_{u}^{*}\left(w_{i}, \theta\right)<\theta$ (i.e., if $\theta \geq \hat{\theta}_{i}$ ) (see Figure 2) but are not if $\theta_{u}^{*}\left(w_{i}, \theta\right)>\theta$ (i.e., if $\theta<\hat{\theta}_{i}$ ) (see Figure 3 ).

Insert Figures 2 and 3 around here

The following proposition studies which parents most-prefer a university size compatible with their child becoming high-skilled. 
Proposition 1 For each parent's income level $w_{i}$, there exists a unique value of $\theta$, denoted by $\tilde{\theta}_{i}$, such that all agents with $\theta<\tilde{\theta}_{i}$ most-prefer putting their kids in a vocational school with $\theta_{u}=\theta_{u}^{*}\left(w_{i}, \theta\right)>\tilde{\theta}_{i}$, while all $\theta>\tilde{\theta}_{i}$ most-prefer enrolling their kid at the smallest university that accepts him: $\theta_{u}=\theta$. Moreover, we have that $\tilde{\theta}_{i}<\hat{\theta}_{i}$.

Proof. See Appendix A

The parent of a higher ability child benefits relatively more from going to university, for two reasons: (i) the child benefits more from the skill premium $\omega_{u}-\omega_{V}$ and (ii) it is socially (and individually) less costly for the university to enrol his child (because the implied size of the university, and thus its tax cost, is lower). This explains why there exists a unique threshold value of $\theta$ below (resp., above) which parents most-prefer a university size consistent with their child becoming low-skilled (resp., high-skilled).

The next lemma performs the comparative statics analysis of this threshold individual $\tilde{\theta}_{i}$

Lemma $3 \tilde{\theta}$ is decreasing in $\delta$ with $\tilde{\theta}_{L}<\tilde{\theta}_{H}$.

Proof. $\tilde{\theta}_{i}$ is such that $U_{u}^{*}\left(w_{i}, \theta\right)-U_{V}^{*}\left(w_{i}, \theta\right)=0$. Applying the implicit function theorem, we obtain that

$$
\begin{aligned}
\frac{\partial \tilde{\theta}_{i}}{\partial w_{i}} & =-\frac{t\left(\theta_{u}^{*}\left(w_{i}, \tilde{\theta}_{i}\right)\right)-t\left(\tilde{\theta}_{i}\right)}{-w_{i} t^{\prime}\left(\tilde{\theta}_{i}\right)+\delta\left[\omega_{u}-\omega_{V}\left(\theta_{u}^{*}\left(w_{i}, \tilde{\theta}_{i}\right)\right)\right]} \\
& >0, \text { since } \tilde{\theta}_{i}<\hat{\theta}_{i}(\text { Proposition 1) and by Lemma 2, } \\
\frac{\partial \tilde{\theta}_{i}}{\partial \delta} & =-\frac{\tilde{\theta}_{i}\left[\omega_{u}-\omega_{V}\left(\theta_{u}^{*}\left(w_{i}, \tilde{\theta}_{i}\right)\right)\right]}{-w_{i} t^{\prime}\left(\tilde{\theta}_{i}\right)+\delta\left[\omega_{u}-\omega_{V}\left(\theta_{u}^{*}\left(w_{i}, \tilde{\theta}_{i}\right)\right)\right]}<0 .
\end{aligned}
$$

Recall that individual $\tilde{\theta}_{i}$ is indifferent between the smallest university accepting his child $\left(\theta_{u}=\tilde{\theta}_{i}\right)$ and a smaller $\left(\right.$ at $\left.\theta_{u}^{*}\left(w_{i}, \tilde{\theta}_{i}\right)>\tilde{\theta}_{i}\right)$ university system that would exclude his child. A richer individual pays a larger fraction of the cost of the university system, and thus has to be the parent of a more gifted child to be indifferent between the two options. Alternatively, a more altruistic parent puts more weight on the skill premium enjoyed by 
university graduates and thus has to be the father of a less gifted child to be indifferent between the two options.

We now move to the determination of the majority voting equilibrium threshold ability.

\section{Majority voting equilibrium}

We first introduce this straightforward definition.

Definition 1 Let $\theta_{u}^{M V}$ be the median most-preferred value of $\theta_{u}$ in the population.

The following lemma compares $\theta_{u}^{M V}$ with $\theta_{\text {med }}$.

Lemma 4 (a) $\theta_{u}^{M V}$ is unique. (b) If $\theta_{u}^{*}\left(w_{H}, \underline{\theta}\right)<\theta_{\text {med }}$ then $\theta_{u}^{M V}=\theta_{\text {med }}$, (c) otherwise $\theta_{u}^{M V}>\theta_{\text {med }}$

Proof. (a) Follows from the facts that $\theta_{u}^{*}\left(w_{i}, \theta\right)$ and $\theta$ are continuous and strictly monotone in $\theta$ for $i \in\{L, H\}$ and that $f(\theta)$ has full support. (b) If $\theta_{u}^{*}\left(w_{H}, \underline{\theta}\right)<\theta_{\text {med }}$ then $\tilde{\theta}_{L}<\tilde{\theta}_{H}<\theta_{\text {med }}\left(\right.$ since $\partial \theta_{u}^{*}\left(w_{i}, \theta\right) / \partial \theta<0$ and $\left.\partial \tilde{\theta}_{i} / \partial w_{i}>0\right)$ so that all $\theta>\theta_{\text {med }}$ most-prefer $\theta_{u}=\theta>\theta_{\text {med }}$, while all $\theta<\theta_{\text {med }}$ most-prefer either $\theta_{u}=\theta<\theta_{\text {med }}$ or $\theta<\theta_{u}^{*}\left(w_{i}, \theta\right)<\theta_{\text {med }}\left(\right.$ since $\left.\partial \theta_{u}^{*}\left(w_{i}, \theta\right) / \partial \theta<0\right)$. Hence $\theta_{u}^{M V}=\theta_{\text {med }}$. (c) If $\theta_{u}^{*}\left(w_{H}, \underline{\theta}\right)>\theta_{\text {med }}$ then it is clear that more than one half of the polity (made of rich parents with low ability children, and of parents of higher-than- $\theta_{\text {med }}$ ability children ) most-prefer a higher-than $\theta_{\text {med }}$ value of $\theta_{u}$. It is then straightforward that $\theta_{u}^{M V}>\theta_{\text {med }}$.

Lemma 4 is straightforward when one looks at Figures 4 (Lemma 4(b)) and 5 (Lemma $4(\mathrm{c}))$.

Insert Figures 4 and 5 around here

Proposition 2 proves the existence of a majority voting equilibrium and shows that it can be of two types. It makes use of the following assumption. 
Assumption $1 \max \left[\theta_{u}^{*}\left(w_{H}, \tilde{\theta}_{H}\right), \theta_{u}^{*}\left(w_{L}, \tilde{\theta}_{L}\right)\right] \leq \theta_{u}^{M V}$

Assumption 1 is essentially technical and guarantees the existence of a Condorcet winner when voting over $\theta_{u}{ }^{16}$

Proposition 2 (a) If $\theta_{u}^{*}\left(w_{H}, \underline{\theta}\right)<\theta_{\text {med }}$, then $\theta_{u}^{M V}=\theta_{\text {med }}$ is the unique Condorcet winning value of $\theta_{u}$. (b) If $\theta_{u}^{*}\left(w_{H}, \underline{\theta}\right)>\theta_{\text {med }}$ and if Assumption 1 is satisfied, then $\theta_{u}^{M V}>\theta_{\text {med }}$ is the unique Condorcet winning value of $\theta_{u}$.

\section{Proof. See Appendix C}

The type of majority voting equilibrium, as well as the equilibrium size of the university system, depend crucially on the preferences of a rich parent with the lowest ability child. If such a parent (who most-prefers not to enrol his child at university) prefers a relatively large university system, then the decisive voters are the (poor and rich) parents of a child with median skill and we obtain a "classical equilibrium" where half of students are enrolled in the university and where the top half of the ability distribution favors a smaller university while the bottom half favors a larger one (see Figure 4). Among those who favor a larger university, parents of low ability children do this in order to boost the vocational wage of their child while parents of children with larger abilities would like their child to become highly skilled. Observe that a university system enrolling one half of the student population is precisely the target of current French policy (and of UK policy under Prime Minister Blair).

If the rich parent of the lowest ability child prefers a relatively small university system (and if Assumption 1 is satisfied), the majority voting equilibrium is of the "ends-againstthe-middle" type (see Figure 5), with four decisive voters, and where parents with either low or high (strictly larger than median) ability children prefer a smaller university size (to decrease their tax bill in both cases), while parents of children with medium abilities

\footnotetext{
${ }^{16}$ We refer the reader to Appendix B for a description of the equilibrium existence issues faced when Assumption 1 is not satisfied.
} 
prefer a larger university system (to enable access to university for the higher ability children in this group, and to further boost the vocational wage for the lower ability group). The equilibrium proportion of children attending university is strictly less than one half, which corresponds to the stylized fact reported in the Introduction. ${ }^{17}$

We now compare the majority chosen value of $\theta_{u}$ with its Pareto efficient level, before performing its comparative statics analysis.

\section{Comparison with the Pareto efficient allocation}

With our quasi linear framework, the Pareto efficient allocation corresponds to the one chosen by a utilitarian social planner maximizing the sum of individual utilities. ${ }^{18}$ Assuming to simplify, in this section, that there is a single parental income level $w$, the optimal value of $\theta_{u}$ would maximize

$$
\delta \int_{\underline{\theta}}^{\theta_{u}} \theta \omega_{V}\left(\theta_{u}\right) d F(\theta)+\delta \int_{\theta_{u}}^{\bar{\theta}} \theta \omega_{u} d F(\theta)-c_{u}\left(1-F\left(\theta_{u}\right)\right),
$$

with the following FOC, where $\theta_{u}^{W}$ denotes the Pareto optimum, ${ }^{19}$

$$
c_{u}=\delta\left[\theta_{u}^{W}\left(\omega_{u}-\omega_{V}\left(\theta_{u}^{W}\right)\right)-\frac{\partial \omega_{V}\left(F\left(\theta_{u}^{W}\right)\right)}{\partial F} \int_{\underline{\theta}}^{\theta_{u}^{W}} \theta d F(\theta)\right] .
$$

The LHS of (6) denotes the marginal social benefit of increasing $\theta_{u}$, while the RHS represents its marginal cost. The latter can be decomposed into two effects: the first

\footnotetext{
${ }^{17}$ If $\alpha=0$ (see footnote 11) so that unskilled wages do not increase with $\theta$, then the optimal university size of parents whose children do not go to university is no longer strictly monotone (as the proof of lemma 4 requires) but constant. In that case, the majority voting equilibrium is always a classical one, with $50 \%$ attending university.

${ }^{18}$ We assume that the social planner takes only parents' utilities into account. This allows for a meaningful comparison with the equilibrium under majority voting. Adding the utility of the children would overweigh them in the social welfare function, since parents already care for them. See footnote 20 for the impact of such a move on the Pareto efficient level of $\theta_{u}$.

${ }^{19}$ Observe that the SOC holds since $\partial^{2} \omega_{V}\left(F\left(\theta_{u}\right)\right) / \partial F^{2}<0$.
} 
term represents the loss of the skill premium by the marginal agent $\theta_{u}$ who loses access to university, while the second term measures the decrease in vocational wage of all lowskilled agents when the university size is decreased.

We now compare this Pareto efficient level $\theta_{u}^{W}$ with the one chosen under majority voting. We concentrate on the ends-against-the-middle equilibrium. Denoting by $\theta_{d e c}$ the decisive voter who most-prefers $\theta_{u}^{M V}>\theta_{\text {dec }}$ (i.e., whose child becomes low-skilled, see Figure 5), the FOC for $\theta_{u}^{M V}$ is

$$
c_{u}=-\delta \theta_{d e c} \frac{\partial \omega_{V}\left(F\left(\theta_{u}^{M V}\right)\right)}{\partial F}=0
$$

The decisive voter $\theta_{\text {dec }}$ does not consider the first marginal cost of increasing $\theta_{u}$, namely the loss of the skill premium by the marginal student $\theta_{u}^{M V}$. Moreover, the decisive voter considers only the impact of $\theta_{u}$ on the vocational wage of his child, rather than on all low-skilled agents. We then obtain the following sufficient condition for the two effects to reinforce each other..$^{20}$

Proposition 3 In an ends-against-the-middle equilibrium with a single parental income level, a sufficient condition for the majority chosen university size to be too small compared to its Pareto efficient level, $\theta_{u}^{M V}>\theta_{u}^{W}$, is that

$$
\theta_{d e c}<\int_{\underline{\theta}}^{\theta_{u}^{W}} \theta d F(\theta) .
$$

\section{Comparative statics analysis of the majority cho- sen ability threshold level}

With the classical equilibrium, we have $\theta_{u}^{M V}=\theta_{\text {med }}$, so that the result that $50 \%$ of students go to university is not affected by changes in parameters of the model. We

\footnotetext{
${ }^{20}$ Putting more weight on children's utilities in the social welfare function is equivalent to increasing $\delta$ in (6) but not in (7) and would result in a lower value of $\theta_{u}^{W}$, adding to these two effects in the same direction. Proposition 3 would then hold a fortiori.
} 
then investigate the circumstances under which an ends-against-the-middle equilibrium emerges, as well as how the majority voting size of the university sector is affected in that equilibrium.

Proposition 4 (a) The following six factors render an ends-against-the-middle equilibrium more likely :

(i) a more expensive university, $c_{u}$,

(ii) a smaller degree of altruism of parents, $\delta$,

(iii) a vocational wage less sensitive to supply (i.e., a smaller absolute value of $\left.\partial \omega_{V}(F) / \partial F\right)$, (iv) a larger income inequality (in the form of a means-preserving spread of income levels),

(v) a poorer society (i.e., a larger proportion $\lambda$ of low income agents, driving the average income down) and

(vi) a lower minimum ability level of children (keeping $\theta_{\text {med }}$ constant).

(b) The first three factors listed above also decrease the size of the university (i.e., increase the value of $\theta_{u}^{M V}$ ) in an ends-against-the-middle equilibrium. Factor (iv) also increases $\theta_{u}^{M V}$ provided that income inequality is large enough to start with. Factors (v) and (vi) have an ambiguous impact on $\theta_{u}^{M V}$.

Proof. See Appendix D.

An ends-against-the-middle equilibrium occurs when the rich parent of the child with the lowest ability level most-prefers a public university enrolling less than one half of the students. All factors increasing $\theta_{u}^{*}\left(w_{H}, \underline{\theta}\right)$ without affecting $\theta_{\text {med }}$ then make such an equilibrium more likely. Three factors make the university system more expensive for this individual: a larger income level (since tax financing of universities is proportional to income), a smaller average income (i.e., tax base) and a larger cost per student $c_{u}$. Three factors decrease the benefit of a large university for this individual: a less altruistic society, a lower minimum level of ability and a smaller sensitivity of the vocational wage to the number of low-skilled workers (the latter two factors decrease the incentive to restrict the supply of low skills in order to increase the child's vocational wage). 
A more costly university, a lower level of altruism and a lower responsiveness of the reference vocation wage to the fraction of low skilled laborers increase $\theta_{u}^{*}$ for all voters, and thus increase $\theta_{u}^{M V}$ as well. The impact of these three variables on the type and size of equilibrium is then consistent, since they make the university system smaller in both cases.

A higher income inequality decreases the most-preferred university size of rich parents of low ability children (because their tax bill increases) but increases that of the poor parents (for the symmetrical reason). If income inequality is large enough so that all poor parents most-prefer a larger university size than the one chosen under majority voting in an ends-against-the-middle equilibrium, the latter effect has no impact on the median most-preferred size, while the former effect decreases this median most-preferred size.

Finally, increasing the proportion of poor people has two effects of opposite signs on $\theta_{u}^{M V}$ : a negative direct impact (since poor people prefer a lower value of $\theta_{u}^{*}$ than rich people of the same ability) and a positive indirect impact (by decreasing the average income, inducing all voters to prefer a higher value of $\theta_{u}^{*}$ ), so that the overall impact remains ambiguous. Likewise, since the identity of the decisive voters in an ends-againstthe-middle equilibrium depends on the whole distribution of $\theta$, decreasing $\underline{\theta}$ while keeping $\theta_{\text {med }}$ constant has an ambiguous impact on $\theta_{u}^{M V}$.

Observe that introducing some correlation between $w$ and $\theta$ (while keeping the marginal distributions of skills and of income unchanged) does not affect the nature of the voting equilibrium (classical or ends-against-the-middle), because the introduction of correlation does not impact the government's budget constraint (since all children whose ability is above the chosen threshold go to university, whatever the income level of their parent). We now study the impact of the correlation between income and ability on the size of the university in an ends-against-the-middle equilibrium.

We introduce a positive correlation between $w$ and $\theta$ using the concept of "medianpreserving spread" introduced by Allison and Foster (2004). Assume that we have

$$
F(\theta)=\lambda F_{L}(\theta)+(1-\lambda) F_{H}(\theta)
$$


where $F_{i}(\theta)$ denotes the distribution function of $\theta$ among parents with income $w_{i}$, and $f_{i}(\theta)$ the corresponding density function. We assume that these density functions satisfy

$$
\begin{aligned}
& f_{L}(\theta) \geq f_{H}(\theta) \text { for all } \theta<\theta_{\text {med }} \\
& f_{L}(\theta) \leq f_{H}(\theta) \text { for all } \theta>\theta_{\text {med }}
\end{aligned}
$$

The case with no correlation between income and ability corresponds to $f_{L}=f_{H}$ for all $\theta$. We increase the correlation between $w$ and $\theta$ by having $f_{L}(\theta)-f_{H}(\theta)$ increase for all $\theta<\theta_{\text {med }}$ and decrease for all $\theta>\theta_{\text {med }}$, while keeping $F(\theta)$ unchanged. In words, for any value of $\theta<\theta_{\text {med }}$, the fraction of children having a $w_{L}$ parent increases, while the opposite occurs for children with $\theta>\theta_{\text {med }}$. Note that $\theta_{\text {med }}$ is not affected, since the marginal distribution $F(\theta)$ is not affected by assumption.

We then obtain the following proposition.

Proposition 5 In an ends-against-the-middle equilibrium with $\theta_{\text {med }} \geq \tilde{\theta}_{H}$, increasing the correlation between $w$ and $\theta$ in the way just defined increases the majority-chosen university size (i.e., lowers $\theta_{u}^{M V}$ ).

Proof. The correlation between income and ability affects neither the type of equilibrium nor individual preferences over $\theta_{u}$, so that $\tilde{\theta}_{H}$ is not affected either. All agents with $\theta>\tilde{\theta}_{H}$ prefer $\theta_{u}=\theta$, whatever their income level, so that the increase in correlation does not affect their preferences. Among agents with $\theta<\tilde{\theta}_{H}$, low income parents most-prefer a lower value of $\theta_{u}$ than high income agents of the same $\theta$ (with $\theta_{u}^{*}\left(w_{L}, \theta\right)<\theta_{u}^{*}\left(w_{H}, \theta\right)$ for $\theta<\tilde{\theta}_{L}$ and $\theta<\theta_{u}^{*}\left(w_{H}, \theta\right)$ for $\left.\tilde{\theta}_{L}<\theta<\tilde{\theta}_{H}\right)$, and the fraction of low income parents among these agents increases provided that $\theta_{\text {med }} \geq \tilde{\theta}_{H}$, hence the result.

The preferences of parents with higher-than- $\tilde{\theta}_{H}$ ability children are not affected by their income, since they most-prefer the smallest university that enrols their children. The preferences over $\theta_{u}$ of parents with $\theta<\tilde{\theta}_{H}$ are affected by their income level, with low-income parents preferring a larger university system (i.e., a lower $\theta_{u}$ ) than rich parents (whether they prefer their child to become highly skilled or not) because of their lower tax cost. Increasing the correlation between income and ability, by increasing the share 
of poor parents among those with lower-than-median abilities, then results in a larger majority chosen size of the university system.

Observe that Proposition 5 is driven not by the increase in the fraction of rich parents with smart kids, but rather by the increase, among children with lower abilities, of the fraction of those with poor parents. Also, since children with $\theta>\theta_{u}^{M V}>\theta_{\text {med }}$ end up attending university, an increase in the correlation between income and ability (in the way defined above) results in a larger fraction of high-skilled children coming from rich families (even though more people get access to universities). A positive correlation between income and ability then increases both the proportion of student attending universities, and the participation gap (defined as the larger proportion of students from rich background among university students than among vocational students).

Observe also that an opposite result would obtain if, rather than introducing a positive correlation between income and ability, we assumed that the proportion of citizens who turn out and vote were increasing with income (a well-known empirical regularity). In that case, turnout would not affect voting results among the agents with $\theta>\tilde{\theta}_{H}$ ( they have the same preferences for $\theta_{u}$ irrespective of their income), but would decrease the fraction of poor voters below $\tilde{\theta}_{H}$, which would result in a smaller equilibrium university. By the same reasoning, a gradual extension of the voting franchise, modeled as an increase in the fraction of poor agents allowed to vote, would result in a larger equilibrium university size

In order to shed more light on the impact of the correlation of income and skills on the equilibrium size of university, we now resort to numerical simulations. We also use these simulations as an opportunity to show that the results obtained in sections 3 and 4 generalize to a setting with a continuous distribution of income, and where parent's utilities are concave in their own consumption.

We then assume in the remainder of this section that the utility of parents is given by

$$
U_{u}\left(\theta_{u}, w_{i}, \theta\right)=u\left(w_{i}\left(1-t\left(\theta_{u}\right)\right)\right)+\delta \theta \omega_{u},
$$


and by

$$
U_{V}\left(\theta_{u}, w_{i}, \theta\right)=u\left(w_{i}\left(1-t\left(\theta_{u}\right)\right)\right)+\delta \theta \omega_{V}\left(\theta_{u}\right)
$$

where the utility function $u($.$) belongs to the constant relative risk aversion (CRRA)$ family,

$$
u(c)=\frac{c^{1-\rho}-1}{1-\rho},
$$

and where the coefficient of relative risk aversion $\rho$ is set to 0.71 , which is the middle value found by Chetty (2006).

We assume that $w$ and $\theta$ are distributed according to the $\operatorname{cdf} H(w, \theta)$ and the pdf $h(w, \theta)$ over the interval $\left[w_{L}, w_{H}\right] X[\underline{\theta}, \bar{\theta}]$. The marginal distribution of $w$ is denoted by $G($.$) for the cdf and g($.$) for the pdf. As in the rest of the paper, the marginal distribution$ of skills is denoted by $F($.$) for the cdf and f($.$) for the pdf. We model the correlation$ between income and skills by using the concept of copula. From Sklar's theorem (Sklar (1959)), there exists a joint distribution $C$ on $[0,1]^{2}$, called a copula, such that its two marginals are uniform on $[0,1]$ and

$$
H(w, \theta)=C(G(w), F(\theta)) .
$$

As an illustration, we assume that both $F$ and $G$ are uniformly distributed, and that the distribution $H$ is obtained using the Archimedean copula

$$
H(w, \theta)=\Phi^{-1}(\Phi(G(w))+\Phi(F(\theta))),
$$

where $\Phi$ is called the generator function. We provide an example with the so-called Gumbel copula, where the generator function is given by

$$
\Phi(x)=(\ln (x))^{-\gamma} .
$$

Increasing $\gamma$ results in an increase in the correlation between $w$ and $\theta$ : the correlation is equal to zero (independence) when $\gamma=1$, and increases to one as $\gamma$ becomes large enough. 
Figure 6 shows the most-preferred value of $\theta_{u}$ as a function of skill and income. ${ }^{21}$ The thick (resp., dashed) curves represent the most-preferred value of $\theta_{u}$ for the highest (resp., lowest) income level $w_{H}$ (resp., $\left.w_{L}\right)$. The black curves represent low-skilled agents who prefer $\theta_{u}^{*}>\theta$ while the blue curves represent agents who most-prefer $\theta_{u}=\theta$. Agents with income in-between $w_{L}$ and $w_{H}$ have most-preferred values of $\theta_{u}$ which are in-between those preferred by $w_{L}$ and $w_{H}$ : we have depicted the first part of the $\theta_{u}^{*}$ curve of agents with the average income $E w=\bar{w}$. The horizontal axes crosses the vertical axes at $\left(\underline{\theta}, \theta_{\text {med }}\right)$. The correlation between income and risk does not affect individual preferences over $\theta_{u}$, but of course affects its majority chosen value. We then have an ends-against-the-middle equilibrium, whatever the correlation between income and risk. Without any correlation, we obtain the value of $\theta_{u}^{M V}$ depicted by the dot dashed horizontal line in Figure 6 . At the equilibrium, $47.8 \%$ of students go to university.

Insert Figure 6 around here

Figure 7 depicts the two coalitions which face each other at this equilibrium, in the (income, skill) space. Agents located below the thick curve tend to be rich parents of low-skilled children, who do not attend university. They are joined by agents above the dashed line, whatever their income level, whose children do attend university. Members of both groups favor a smaller university size. Put together, these two groups represent exactly one half of the population. They face the group located in-between the dashed line and the thick curve, whose members favor a larger university.

Insert Figure 7 around here

We then vary the correlation between income and skill (by increasing the value of $\gamma$ above one, and we report on Figure 8 how this affects the value of $\theta_{u}^{M V}$ ). We see that

\footnotetext{
${ }^{21}$ We assume that $\omega_{u}=100, \omega_{V}(F)=90-80 F^{4}, w_{L}=10, w_{H}=100, \underline{\theta}=0.2, \bar{\theta}=2, \delta=0.2$, and $c_{u}=50$.
} 
a larger positive correlation increases the university size (i.e., lowers the value of $\theta_{u}^{M V}$ ). Our numerical simulations then confirm the results obtained with two income levels in Proposition 5. With our numerical simulations, we obtain at the limit (when $\operatorname{corr}(w, \theta)=$ 1) a classical equilibrium where exactly $50 \%$ of the students attend university. ${ }^{22}$

Insert Figure 8 around here

Finally, we show in Figure 9 how increasing the correlation between parent's income and child's skill affects the composition of the universities' student body. Without any correlation, exactly $47.8 \%$ of children of parents of all income levels attend university. As soon as $\operatorname{corr}(w, \theta)$ is increased, the fraction of children attending university increases with the parent's income (the participation gap). At the same time, the overall fraction of students attending university in the population also increases with $\operatorname{corr}(w, \theta)$. We obtain numerically that this second impact is of second order importance compared to the first. Observe from Figure 9 that the horizontal axis is set at 50\%, and that the intersection between the curves (representing the fraction of children of parents with income $w$ attending university) and this axis moves to the left as the correlation is increased. For instance, when $\operatorname{corr}(w, \theta)=0.14$, parents in the top $28 \%$ of the income distribution (i.e., with $w>75$ ) have more than $50 \%$ chance that their child attend university. This proportion increases monotonically with income and with the correlation between income and skill. At the limit, when income and skill are perfectly positively correlated, university is composed exclusively of all children of parents in the top half of the income distribution.

\section{Insert Figure 9 around here}

We now show that our analysis is robust to the introduction of private schooling alternatives.

\footnotetext{
${ }^{22}$ With our copula, increasing the correlation means increasing the density around the line joining $\left(w_{L}, \underline{\theta}\right)$ and $\left(w_{\max }, \bar{\theta}\right)$ on Figure 7 , resulting in fewer parents in the zone below the thick curve. At the limit, when $\operatorname{corr}(w, \theta)=1$, all parents are located on this line, and we obtain a classical equilibrium.
} 


\section{Extension to the case with private alternatives}

In this section, we go back to the original formulation of the model presented in section 2 (linear utilities, two income levels, no correlation between income and ability), but we introduce the possibility for parents to choose either tuition-free public education or fee-charging private institutions, both at the vocational and the academic levels. Four alternatives are thus available: to become low-skilled, either by attending a public $(V)$ or private $(\pi)$ vocational school, or to become high-skilled in a public $(u)$ or a private $(e)$ university. ${ }^{23}$ Access to any university remains rationed by ability, with $\theta_{u}$ the minimum level of ability required to be admitted to a (public or private) university and to become high-skilled.

To enrol their child in a private institution, parents must pay tuition fees equal to $c_{\pi}$ for private vocational schools, and to $c_{e}$ for private universities. Students who receive private education are more generously rewarded in the labor market than their publicly educated counterparts. On the one hand, the reference wage of a low-skilled agent attending a public vocational school, $\omega_{V}$, remains a decreasing function of the proportion of low skilled workers, irrespective of whether they graduate from a private or public school, while the reference wage of high-skilled agents graduating from a public university remains given by the exogenous $\omega_{u}$. On the other hand, privately educated workers receive a mark-up over these reference wages. The reference wage for high-skilled agents is $\omega_{u}+\Delta_{e}$ if they graduate from a private university, with $\Delta_{e}>0$ exogenously given. The corresponding wage for an agent of ability $\theta$ is then $\theta\left(\omega_{u}+\Delta_{e}\right)$, so that the wage premium for attending the private (as opposed to public) university is $\theta \Delta_{e}$. Likewise, the reference wage for low-skilled agents is equal to $\omega_{V}\left(\theta_{u}\right)+\Delta_{\pi}$ when graduating from a private vocational institution; the corresponding wage for an agent of ability $\theta$ is $\theta\left(\omega_{V}\left(\theta_{u}\right)+\Delta_{\pi}\right)$ and the wage premium for attending the private (as opposed to public) vocational school is $\theta \Delta_{\pi}>0$.

\footnotetext{
${ }^{23}$ Private vocational education may also be interpreted as lower quality university education. In that case, three types of higher education institutions would coexist: low quality private universities, elite private universities and public universities of intermediate quality.
} 
As previously, parents care both about their own consumption (after-tax income) and about the future wage of their child. The utility of a parent of income $w_{i}$ whose child has ability $\theta \geq \theta_{u}$ is represented by $U_{u}\left(\theta_{u}, w_{i}, \theta\right)$ as described in (1) if his child attends a public university, and by

$$
U_{e}\left(\theta_{u}, w_{i}, \theta\right)=w_{i}\left(1-t\left(\theta_{u}\right)\right)+\delta \theta\left(\omega_{u}+\Delta_{e}\right)-c_{e}
$$

if his child attends a private university. Likewise, the utility of a parent of income $w_{i}$ whose child has ability $\theta<\theta_{u}$ is represented by $U_{V}\left(\theta_{u}, w_{i}, \theta\right)$ as described in (2) if his child attends a public vocational school, and by

$$
U_{\pi}\left(\theta_{u}, w_{i}, \theta\right)=w_{i}\left(1-t\left(\theta_{u}\right)\right)+\delta \theta\left(\omega_{V}\left(\theta_{u}\right)+\Delta_{\pi}\right)-c_{\pi}
$$

if the child receives private vocational education.

The timing of the model is unchanged. In the last stage, parents choose where to enrol their child. We assume that the skill premium is always positive, i.e. $\omega_{u}>\omega_{V}(\underline{\theta})+\Delta_{\pi}$. This ensures that parents do enrol their child at university as soon as $\theta \geq \theta_{u}$, as previously. In that case, and comparing (1) with (8), we obtain that they prefer private to public universities if $\theta>\theta_{e u}$ where

$$
\theta_{e u}=\frac{c_{e}}{\delta \Delta_{e}}
$$

i.e., if the gain for the parent of a higher market wage for his child, $\delta \theta \Delta_{e}$, is larger than the tuition fees $c_{e}$. Note that $\theta_{e u}$ depends only on exogenous parameters and that it is independent of household income. From now on, we will then use the term of "elite" private universities, since they cater to the children with the highest abilities.

If $\theta<\theta_{u}$, then parents prefer the private vocational school to the public one if $\theta>\theta_{\pi V}$ where

$$
\theta_{\pi V}=\frac{c_{\pi}}{\delta \Delta_{\pi}}
$$

In order to allow for the four alternatives to coexist at equilibrium, we assume that $\underline{\theta}<\theta_{\pi V}<\theta_{e u}<\bar{\theta}$, which requires the cost per unit of wage premium to be larger for the 
elite universities than for private vocational schools:

$$
\frac{c_{e}}{\Delta_{e}}>\frac{c_{\pi}}{\Delta_{\pi}}
$$

The above two thresholds, along with the minimum ability required to attend university, fully characterize second stage choices. If $\theta_{\pi V}<\theta_{u}<\theta_{e u}$, then children with abilities $\theta<\theta_{\pi V}$ go to public vocational schools, those with $\theta_{\pi V} \leq \theta<\theta_{u}$ go to private vocational schools, those with $\theta_{u} \leq \theta \leq \theta_{e u}$ go to public universities and those with $\theta>\theta_{e u}$ attend private universities. In that case, all four types of schools are active at equilibrium. If $\theta_{u}<\theta_{\pi V}$, then no one attends private vocational schools, since all $\theta<\theta_{u}$ attend public ones. If $\theta_{u}>\theta_{e u}$, then no one attends public universities, since all those with $\theta>\theta_{u}$ go to private ones.

The government budget constraint then becomes

$$
\begin{aligned}
t & =\frac{c_{u}}{\bar{w}}\left(F\left(\theta_{e u}\right)-F\left(\theta_{u}\right)\right) \text { if } \theta_{e u}>\theta_{u} \\
& =0 \text { if } \theta_{e u} \leq \theta_{u}
\end{aligned}
$$

We now show that parents' preferences over $\theta_{u}$ are basically unchanged when we introduce private alternatives. The preferences of parents whose children attend a university are such that

$$
\frac{\partial U_{u}\left(\theta_{u}, w_{i}, \theta\right)}{\partial \theta_{u}}=\frac{\partial U_{e}\left(\theta_{u}, w_{i}, \theta\right)}{\partial \theta_{u}}=-t^{\prime}\left(\theta_{u}\right) w_{i}
$$

where

$$
\begin{aligned}
t^{\prime}\left(\theta_{u}\right) & =-\frac{c_{u}}{\bar{w}} f\left(\theta_{u}\right) \text { if } \theta_{e u}>\theta_{u} \\
& =0 \text { if } \theta_{e u} \leq \theta_{u} .
\end{aligned}
$$

The key observation is that, although private alternatives make public universities cheaper for the tax payers, they do not affect the marginal tax benefit when the threshold $\theta_{u}$ is increased, except if $\theta_{u}$ is large enough that no one attends public universities, in which case the marginal tax benefit is nil. 
The most-preferred value of $\theta_{u}$ of a parent whose child is low skilled is given by

$$
\begin{aligned}
\frac{\partial U_{V}\left(\theta_{u}, w_{i}, \theta\right)}{\partial \theta_{u}} & =\frac{\partial U_{\pi}\left(\theta_{u}, w_{i}, \theta\right)}{\partial \theta_{u}} \\
& =\delta \theta \frac{\partial \omega_{V}\left(F\left(\theta_{u}^{*}\right)\right)}{\partial F} f\left(\theta_{u}\right)-t^{\prime}\left(\theta_{u}\right) w_{i} .
\end{aligned}
$$

This condition is equivalent to (4) when $\theta_{e u}>\theta_{u}$. When $\theta_{e u} \leq \theta_{u}$, we obtain that (12) is always negative, since further increases in $\theta_{u}$ decrease the reference wage $\omega_{V}$ but do not decrease the individual's tax payment, which is nil. We then have that $\theta_{u}^{*}\left(w_{i}, \theta\right) \leq \theta_{e u}$, and in order to concentrate on interior solutions, we assume from now on that this inequality is strict for all agents. ${ }^{24}$

We then obtain that our previous results (lemmas and propositions relating to the existence, type, size and comparative statics of the equilibrium) carry through to the case with private alternatives. ${ }^{25}$ The intuition for this robustness of our results is that the most-preferred values of $\theta_{u}$, namely $\theta_{u}^{*}\left(w_{i}, \theta\right)$ (when $\left.\theta<\tilde{\theta}_{i}\right)$ and $\theta_{u}=\theta\left(\text { when } \theta \geq \tilde{\theta}_{i}\right)^{26}$ are not affected by the introduction of private alternatives, which simply shift upward (by $\delta \theta \Delta_{\pi}-c_{\pi}$ if $\theta>\theta_{\pi V}$ and $\delta \theta \Delta_{e}-c_{e}$ if $\theta>\theta_{e u}$ ) the utility a parent of type $\theta$ obtains as a function of $\theta_{u}$. More precisely, the type of equilibrium (classical vs ends-against-themiddle) is not affected, because it depends on the comparison of $\theta_{u}^{*}\left(w_{H}, \underline{\theta}\right)$ and $\theta_{\text {med }}$, none of them being affected by the availability of private alternatives. The ability threshold for attending (public or private) universities in an ends-against-the-middle equilibrium, $\theta_{u}^{M V}$, is not affected either, even though $\tilde{\theta}_{i}$ may be affected..$^{27}$ This is due to the fact that variations in $\tilde{\theta}_{i}$ only affect individuals with $\theta<\theta_{u}^{*}\left(w_{i}, \tilde{\theta}_{i}\right)<\theta_{u}^{M V}$ under Assumption 1.

\footnotetext{
${ }^{24}$ This is the equivalent of our assumption that $\theta_{u}^{*}\left(w_{i}, \theta\right)<\bar{\theta}$ in section 3 .

${ }^{25}$ Proofs available upon request.

${ }^{26}$ Parents of type $\theta>\theta_{e u}$ are actually indifferent between any $\theta_{u} \in\left[\theta_{e u}, \theta\right]$. This does not affect our results provided that $\theta_{\text {med }}<\theta_{e u}$-i.e., that less than $50 \%$ of children attend private universities, a most reasonable assumption.

${ }^{27}$ If $\tilde{\theta}_{H}<\theta_{\pi V}$, then the availability of private alternatives does not impact $\tilde{\theta}_{i}$ since agents of that type do not make use of any private institution. If $\theta_{\pi V}<\tilde{\theta}_{i}<\theta_{e u}$, then the availability of private alternatives increases $\tilde{\theta}_{i}$ because the private alternative is used by agents of that type if they attend a vocational school $(\pi)$ but not if they go to university $(u)$. Finally, we can exclude the case where $\tilde{\theta}_{i}>\theta_{\text {eu }}$, because $\theta_{u}^{*}\left(w_{H}, \underline{\theta}\right)<\theta_{e u}$ (by assumption) and because $\partial \theta_{u}^{*}\left(w_{i}, \theta\right) / \partial \theta<0$ (by Lemma 1$)$.
} 
Whether these individuals prefer their child to become low-skilled (with $\theta_{u}=\theta_{u}^{*}\left(w_{i}, \theta\right)$ ) or high-skilled (with $\theta_{u}=\theta$ ) then does not affect the median most-preferred value of $\theta_{u}$, $\theta_{u}^{M V}$.

The following proposition studies how the Pareto efficient level of $\theta_{u}$ is affected by the availability of private alternatives, and how it compares with the majority-chosen level in an ends-against-the-middle equilibrium with a single parental income level.

Proposition 6 In an ends-against-the-middle equilibrium with a single parental income level,

(a) If $\theta_{u}^{W}$ without private alternatives is lower than $\theta_{\pi V}$, then the availability of private alternatives does not impact the value of $\theta_{u}^{W}$.

(b) If $\theta_{u}^{W}$ without private alternatives is larger than $\theta_{\pi V}$ (but lower than $\theta_{\text {eu }}$ ), then the availability of private alternatives increases the value of $\theta_{u}^{W}$.

(c) In both cases, Proposition 3 remains unchanged.

Proof. See Appendix $E^{28}$

In part (a), the introduction of private alternatives decreases the absolute cost (for society and for the decisive voter) of the public university system, but does not affect the marginal trade-offs of increasing $\theta_{u}$, because no student goes to a private vocational school. In part (b), increasing $\theta_{u}$ moves the marginal student from a public university to a private vocational school. This is less detrimental to welfare than moving the same student to a public vocational school, because the net benefit for a parent of enrolling his child in a private (as opposed to public) vocational school, $\delta \theta_{u} \Delta_{\pi}-c_{\pi}$, is positive. We then obtain that $\theta_{u}^{W}$ increases, compared to the case with no private alternative. Finally, part (c) shows that, even though $\theta_{u}^{W}$ is (weakly) larger with private alternatives than without, while $\theta_{u}^{M V}$ is unchanged, the condition mentioned in Proposition 3 remains sufficient to

\footnotetext{
${ }^{28}$ As explained above, we concentrate on the case where $\theta_{u}^{*}(w, \theta)<\theta_{e u}$ for all $\theta$, so that $\theta_{u}^{M V}<\theta_{e u}$ in any ends-against-the-middle equilibrium, and it makes little sense to cover the -empirically irrelevantcase where $\theta_{u}^{W}>\theta_{e u}$.
} 
have $\theta_{u}^{M V}>\theta_{u}^{W}$. The intuition for this result is that the decisive voter under-estimates the marginal cost of increasing $\theta_{u}$ in the same way as before, but now also over-estimates its marginal benefit (since the marginal social benefit is $c_{u}-c_{\pi}$, while the marginal private benefit for the decisive voter, through a decrease in his tax bill, is $c_{u}$ ).

\section{Conclusion}

In this paper, we have built a simple model to assess the political support for higher education in a setting where university admission is conditioned on a minimum ability level. The model developed is very parsimonious but, as detailed in numerous footnotes throughout the analysis, the results we obtain are robust to the introduction of several natural extensions, such as a continuum of parental income levels, parent's utility concave in their own consumption, uncertainty as to the future income of the child, costly vocational schools, non proportional taxation, university peers effects, and an endogenous high skilled reference wage.

We finish by mentioning two (among many) dimensions in which the model can be generalized. First, although we have shown that our results are robust to the introduction of private, fee supported schooling alternatives, we have assumed that no parent is credit constrained. Relaxing this assumption would move the model closer to reality, and would open up a role for subsidies. Second, one of the most interesting results obtained above shows that a larger correlation between parent's income and child's ability results in a larger university system. Our model takes this correlation as given. We would like to endogenize it, for instance by adding a preliminary stage to the model where parents can spend resources to improve their child's results on the test determining their access to university. Credit constraints would also play a crucial role in this case. 


\section{Appendix A: Proof of Proposition 1}

We denote by

$$
U_{u}^{*}\left(w_{i}, \theta\right)=U_{u}\left(\theta, w_{i}, \theta\right)
$$

the highest utility level a parent of type $(\theta, i)$ can attain by sending his child to university (i.e., when setting $\theta_{u}=\theta$ ), and by

$$
U_{V}^{*}\left(w_{i}, \theta\right)=U_{V}\left(\theta_{u}^{*}\left(w_{i}, \theta\right), w_{i}, \theta\right)
$$

the highest utility level attained when his child attends vocational school (i.e., when setting $\left.\theta_{u}=\theta_{u}^{*}\left(w_{i}, \theta\right)\right)$. We have

$$
U_{u}^{*}\left(w_{i}, \theta\right)-U_{V}^{*}\left(w_{i}, \theta\right)=w_{i}\left[t\left(\theta_{u}^{*}\left(w_{i}, \theta\right)\right)-t(\theta)\right]+\delta \theta\left[\omega_{u}-\omega_{V}\left(\theta_{u}^{*}\left(w_{i}, \theta\right)\right)\right]
$$

Using the envelope theorem, we obtain

$$
\frac{\partial\left(U_{u}^{*}\left(w_{i}, \theta\right)-U_{V}^{*}\left(w_{i}, \theta\right)\right)}{\partial \theta}=-w_{i} t^{\prime}(\theta)+\delta\left[\omega_{u}-\omega_{V}\left(\theta_{u}^{*}\left(w_{i}, \theta\right)\right)\right]>0 .
$$

It is easy to see that $\lim _{\theta \rightarrow 0} U_{u}^{*}\left(w_{i}, \theta\right)<\lim _{\theta \rightarrow 0} U_{V}^{*}\left(w_{i}, \theta\right)$ since $\lim _{\theta \rightarrow 0} \theta_{u}^{*}\left(w_{i}, \theta\right)=\bar{\theta}$ so that $t(\bar{\theta})<\lim _{\theta \rightarrow 0} t(\theta)$, while $U_{u}^{*}\left(w_{i}, \bar{\theta}\right)<U_{V}^{*}\left(w_{i}, \bar{\theta}\right)$ since $\theta_{u}^{*}\left(w_{i}, \bar{\theta}\right)>0$ and $\omega_{V}\left(\theta_{u}^{*}\left(w_{i}, \bar{\theta}\right)\right)<\omega_{u}$. Hence the existence and unicity of $\tilde{\theta}_{i}$. Moreover, $U_{u}^{*}\left(w_{i}, \hat{\theta}_{i}\right)>U_{V}^{*}\left(w_{i}, \hat{\theta}_{i}\right)$, implying that $\tilde{\theta}_{i}<\hat{\theta}_{i}$.

\section{Appendix B: Assumption 1}

To convey the intuition for why Assumption 1 is necessary to guarantee the existence of a majority voting equilibrium when $\theta_{u}^{*}\left(w_{H}, \underline{\theta}\right)>\theta_{\text {med }}$, assume that there is only one income level, $w$. Figure 10a shows a situation under which Assumption 1 is not satisfied. In that case, the individual $\tilde{\theta}$ is indifferent between $\theta_{u}=\tilde{\theta}<\theta_{u}^{M V}$ and $\theta_{u}^{*}(w, \tilde{\theta})>\theta_{u}^{M V}>\tilde{\theta}$. Figure 10b reports the utility function $U\left(\theta_{u}, w, \tilde{\theta}\right)$ of individual $\tilde{\theta}$. It is clear that, unlike in the proof of Proposition 2 (b), $\theta_{u}^{M V}$ is not preferred to all $\theta<\theta_{u}^{M V}$ by individual $\tilde{\theta}$, since this individual attains a higher utility level with $\theta_{u}=\tilde{\theta}-\varepsilon$ with $\varepsilon>0$ low enough. This opens up the possibility of a Condorcet cycle and of the inexistence of a Condorcet winning value of $\theta_{u}$. 
Insert Figures 10a and 10b here

Observe that Assumption 1 is not satisfied when

$$
F\left(\theta_{u}^{*}(w, \tilde{\theta})\right)-F(\tilde{\theta})>1 / 2
$$

which implies that $\left.\theta_{\text {med }} \in\right] \tilde{\theta}, \theta_{u}^{*}(w, \tilde{\theta})[$-i.e., that a large fraction of the population is concentrated around the median ability level.

\section{Appendix C: Proof of Proposition 2}

(a) Assume that $\theta_{u}^{*}\left(w_{H}, \underline{\theta}\right)<\theta_{\text {med }}$, so that we claim that $\theta_{u}^{M V}=\theta_{\text {med }}($ see Lemma 4 (a)) is preferred by a majority of parents to any other value of $\theta_{u}$. It is easy to see that all agents with $\theta \geq \theta_{\text {med }}$ prefer $\theta_{\text {med }}$ to any value of $\theta_{u}<\theta_{\text {med }}$ (since $U_{u}\left(\theta_{u}, w_{i}, \theta\right)>U_{V}\left(\theta_{u}, w_{i}, \theta\right)$ when $\theta_{u}<\theta$, and since $U_{u}\left(\theta_{u}, w_{i}, \theta\right)$ increases with $\left.\theta_{u}\right)$. Since they form a majority, $\theta_{\text {med }}$ cannot be beaten by any $\theta_{u}<\theta_{\text {med }}$. We now look at agents with $\theta<\theta_{\text {med }}$. They all have $\theta_{u}^{*}\left(w_{i}, \theta\right)<\theta_{\text {med }}$, since $\theta_{u}^{*}\left(w_{H}, \underline{\theta}\right)<\theta_{\text {med }}$ together with $\partial \theta_{u}^{*}\left(w_{i}, \theta\right) / \partial w_{i}>0$ and $\partial \theta_{u}^{*}\left(w_{i}, \theta\right) / \partial \theta<0$. They then all prefer $\theta_{\text {med }}$ to any $\theta_{u}>\theta_{\text {med }}$, and since they form a majority $\theta_{\text {med }}$ cannot be beaten by any $\theta_{u}>\theta_{\text {med }}$ and constitute the unique Condorcet winner.

(b) Assume that $\theta_{u}^{*}\left(w_{H}, \underline{\theta}\right)>\theta_{\text {med }}$, so that we claim that $\theta_{u}^{M V}>\theta_{\text {med }}$ (see Lemma $4(\mathrm{~b})$ ) is preferred by a majority of parents to any other value of $\theta_{u}$. Since $\partial \theta_{u}^{*}\left(w_{i}, \theta\right) / \partial \theta<0$, its inverse is unique over its range $\left[\theta_{u}^{*}\left(w_{i}, \tilde{\theta}_{i}\right), \theta_{u}^{*}\left(w_{i}, \underline{\theta}\right)\right]$. We then denote by $\theta_{i}^{*}\left(\theta_{u}\right)$ the unique type $\theta$ of a parent of income $w_{i}$ would most-prefer $\theta_{u} \in\left[\theta_{u}^{*}\left(w_{i}, \tilde{\theta}_{i}\right), \theta_{u}^{*}\left(w_{i}, \underline{\theta}\right)\right]$ (and send his child to vocational school) and we define $\theta_{i}^{*}\left(\theta_{u}\right)=\underline{\theta}$ for $\theta_{u}>\theta_{u}^{*}\left(w_{i}, \underline{\theta}\right)$. It is clear that $\theta_{i}^{*}\left(\theta_{u}\right)$ decreases with $\theta_{u}$ on $\left[\theta_{u}^{*}\left(w_{i}, \tilde{\theta}_{i}\right), \theta_{u}^{*}\left(w_{i}, \underline{\theta}\right)\right]$. We then define by

$$
V\left(\theta_{u}\right)=1-F\left(\theta_{u}\right)+\lambda F\left(\theta_{L}^{*}\left(\theta_{u}\right)\right)+(1-\lambda) F\left(\theta_{H}^{*}\left(\theta_{u}\right)\right)
$$

the proportion of parents who most-prefer a larger value of the tracking university threshold than $\theta_{u}$. Note that this set of parents is constituted both of parents of low $\theta$ kids who would not be enrolled at university with this $\theta_{u}$, and of parents of large $\theta$ kids who would 
go to university with this $\theta_{u}$. Observe that $V\left(\theta_{\text {med }}\right)>1 / 2$ and that $\partial V\left(\theta_{u}\right) / \partial \theta_{u}<0$. Assumption 1 guarantees that $V\left(\theta_{u}^{M V}\right)=1 / 2$, so that $\theta_{i}^{*}\left(\theta_{u}^{M V}\right)$ is well defined with $\underline{\theta} \leq \theta_{i}^{*}\left(\theta_{u}^{M V}\right)$ for $i \in\{L, H\}$. Moreover, we have that $\theta_{\text {med }}<\theta_{u}^{M V}<\theta_{u}^{*}\left(w_{H}, \underline{\theta}\right)$.

We now prove that $\theta_{u}^{M V}$ is a Condorcet winner. As in part (a) above, $\theta_{u}^{M V}$ is preferred to any value of $\theta_{u}>\theta_{u}^{M V}$ by the individuals who most-prefer a value of $\theta_{u}$ lower than $\theta_{u}^{M V}$. In this case, this group is made of agents with $\theta_{i}^{*}\left(\theta_{u}^{M V}\right) \leq \theta \leq \theta_{u}^{M V}$ and, by definition of $\theta_{u}^{M V}$, constitutes one half of the electorate. As in part (a) above, agents with $\theta>\theta_{u}^{M V}$ prefer $\theta_{u}^{M V}$ to any smaller value of $\theta_{u}$. We then have to prove that the remaining group, made of parents of low $\theta$ children who favor a larger than $\theta_{u}^{M V}$ value of $\theta_{u}$ also prefer $\theta_{u}^{M V}$ to any lower value of $\theta_{u}$. This group is formed of all parents with $\theta<\theta_{i}^{*}\left(\theta_{u}^{M V}\right)$. For this group, we then have that $\theta<\theta_{u}^{M V} \leq \theta_{u}^{*}\left(w_{i}, \theta\right)$. Since $\partial U_{u}\left(\theta_{u}, w_{i}, \theta\right) / \partial \theta_{u}>0$ and $\partial U_{V}\left(\theta_{u}, w_{i}, \theta\right) / \partial \theta_{u}>0$ for $\theta_{u}<\theta_{u}^{*}\left(w_{i}, \theta\right)$, together with $U_{u}\left(\theta_{u}, w_{i}, \theta\right)>U_{V}\left(\theta_{u}, w_{i}, \theta\right)$ for $\theta_{u}<\theta$, a necessary and sufficient condition for $\theta_{u}^{M V}$ to be preferred to any lower value of $\theta_{u}$ is thus that $U_{u}^{*}\left(w_{i}, \theta\right)<U_{V}\left(\theta_{u}^{M V}, w_{i}, \theta\right)$ for all $\theta<\theta_{i}^{*}\left(\theta_{u}^{M V}\right)$. It is easy to see (from the proof of Lemma 1) that $\partial\left(U_{u}^{*}\left(w_{i}, \theta\right)-U_{V}\left(\theta_{u}^{M V}, w_{i}, \theta\right)\right) / \partial \theta>0$ so that, since $U_{u}^{*}\left(w_{i}, \theta_{i}^{*}\left(\theta_{u}^{M V}\right)\right)<U_{V}\left(\theta_{u}^{M V}, w_{i}, \theta_{i}^{*}\left(\theta_{u}^{M V}\right)\right)$, all agents with $\theta<\theta_{i}^{*}\left(\theta_{u}^{M V}\right)$ strictly prefer $\theta_{u}^{M V}$ to any lower value of $\theta_{u}$. By definition of $\theta_{u}^{M V}$, we then have that (at least) one half of the population share this preference, so that $\theta_{u}^{M V}$ cannot be defeated at the majority voting and is the unique Condorcet winner.

\section{Appendix D: Proof of Proposition 4}

The value of $\theta_{u}^{*}\left(w_{i}, \theta\right)$ is determined by the following FOC (where we have made use of $(3)$ and $(4))$

$$
\delta \theta \frac{\partial \omega_{V}\left(F\left(\theta_{u}\right)\right)}{\partial F}+\frac{w_{i}}{\bar{w}} c_{u}=0
$$

(a) An ends-against-the-middle equilibrium arises when $\theta_{u}^{*}\left(w_{H}, \underline{\theta}\right)>\theta_{\text {med }}$. We then look at all factors that increase $\theta_{u}^{*}\left(w_{H}, \underline{\theta}\right)$, (with $\theta_{\text {med }}$ constant). Repeated application of the implicit function theorem on (15) with $w_{i}=w_{H}$ and $\theta=\underline{\theta}$ then gives results (i) to (vi). (b) (i)-(iii) A larger $c_{u}$, a smaller $\delta$ and a smaller absolute value of $\partial \omega_{V}(F) / \partial F$ all in- 
crease $\theta_{u}^{*}\left(w_{i}, \theta\right)$ for all $w_{i}$ and all $\theta$, and thus increase $\theta_{u}^{M V}$ in an ends-against-the-middle equilibrium. Observe that we need not check their impact on $\tilde{\theta}_{i}$ since, under Assumption 1 , variations in $\tilde{\theta}_{i}$ only affect individuals with $\theta_{u}^{*}\left(w_{i}, \tilde{\theta}_{i}\right)<\theta_{u}^{M V}$.

(b) (iv) If inequality is large enough that $\left.\theta_{u}^{*}\left(w_{L}, \underline{\theta}\right)<\theta_{u}^{M V}<\theta_{u}^{*}\left(w_{H}, \underline{\theta}\right)\right)$ to start with, then a mean-preserving spread of the income distribution, which increases $\theta_{u}^{*}\left(w_{H}, \theta\right)$ but decreases $\theta_{u}^{*}\left(w_{L}, \theta\right)$, unambiguously increases $\theta_{u}^{M V}$ since it increases the fraction of rich parents who favor $\theta_{u}^{*}\left(w_{H}, \theta\right)>\theta_{u}^{M V}$, while keeping unchanged the fraction of poor agents who prefer $\theta_{u}^{*}\left(w_{L}, \theta\right)<\theta_{u}^{M V}$ (since all poor parents are such that $\theta_{u}^{*}\left(w_{L}, \underline{\theta}\right)<\theta_{u}^{M V}$ to start with).

(b) (v) Increasing $\lambda$ decreases $\bar{w}$, which in turn increases $\theta_{u}^{*}\left(w_{i}, \theta\right)$ for all agents. But since there is a larger fraction of poor people, who prefer a lower value of $\theta_{u}^{*}$ than rich people of the same ability, the impact on $\theta_{u}^{M V}$ is ambiguous.

(b) (vi) In an end-against-the-middle equilibrium, the decisive voter is not the individual with the median value of $\theta, \theta_{\text {med }}$, so that keeping $\theta_{\text {med }}$ constant but decreasing $\underline{\theta}$ has an ambiguous impact on $\theta_{u}^{M V}$.

\section{Appendix E: Proof of Proposition 6}

(a) The social objective when $\theta_{u}<\theta_{\pi V}$ is

$$
\begin{aligned}
& \delta\left[\int_{\underline{\theta}}^{\theta_{u}} \theta \omega_{V}\left(\theta_{u}\right) d F(\theta)+\int_{\theta_{u}}^{\theta_{e u}} \theta \omega_{u} d F(\theta)+\int_{\theta_{e u}}^{\bar{\theta}} \theta\left(\omega_{u}+\Delta_{u}\right) d F(\theta)\right] \\
& -c_{u}\left(F\left(\theta_{e u}\right)-F\left(\theta_{u}\right)\right)-c_{e}\left(1-F\left(\theta_{e u}\right)\right),
\end{aligned}
$$

whose FOC with respect to $\theta_{u}^{W}$ is identical to (6).

(b) The social objective, assuming that $\theta_{\pi V}<\theta_{u}<\theta_{e u}$, is

$$
\begin{aligned}
& \delta\left[\int_{\underline{\theta}}^{\theta_{\pi V}} \theta \omega_{V}\left(\theta_{u}\right) d F(\theta)+\int_{\theta_{\pi V}}^{\theta_{u}} \theta\left(\omega_{V}\left(\theta_{u}\right)+\Delta_{\pi}\right) d F(\theta)+\int_{\theta_{u}}^{\theta_{e u}} \theta \omega_{u} d F(\theta)+\int_{\theta_{e u}}^{\bar{\theta}} \theta\left(\omega_{u}+\Delta_{u}\right) d F(\theta)\right] \\
& -c_{u}\left(F\left(\theta_{e u}\right)-F\left(\theta_{u}\right)\right)-c_{\pi}\left(F\left(\theta_{u}\right)-F\left(\theta_{\pi V}\right)\right)-c_{e}\left(1-F\left(\theta_{e u}\right)\right),
\end{aligned}
$$


The FOC with respect to $\theta_{u}^{W}$ can be written as

$$
c_{u}+\left(\delta \theta_{u}^{W} \Delta_{\pi}-c_{\pi}\right)=\delta\left[\theta_{u}^{W}\left(\omega_{u}-\omega_{V}\left(\theta_{u}^{W}\right)\right)-\frac{\partial \omega_{V}\left(F\left(\theta_{u}^{W}\right)\right)}{\partial F} \int_{\underline{\theta}}^{\theta_{u}^{W}} \theta d F(\theta)\right],
$$

with the SOC holding since $\partial^{2} \omega_{V}\left(F\left(\theta_{u}\right)\right) / \partial F^{2}<0$. Comparing (6) and (16), we see that the RHS is identical, while the LHS is larger with (16) when $\theta_{u}^{W}>\theta_{\pi V}$.

(c) We have already established that $\theta_{u}^{M V}$ is not affected by the availability of private alternatives. The value of $\theta_{u}^{W}$ is not affected either if it is lower than $\theta_{\pi V}$. If $\theta_{\pi V}<\theta_{u}^{W}<$ $\theta_{\text {eu }}$, we can reformulate $(16)$ as

$$
c_{u}-c_{\pi}=\delta\left[\theta_{u}^{W}\left(\omega_{u}-\left(\omega_{V}\left(\theta_{u}^{W}\right)+\Delta_{\pi}\right)\right)-\frac{\partial \omega_{V}\left(F\left(\theta_{u}^{W}\right)\right)}{\partial F} \int_{\underline{\theta}}^{\theta_{u}^{W}} \theta d F(\theta)\right] .
$$

Comparing with (6), we see that the decisive voter now over-estimates the marginal benefit of increasing $\theta_{u}$ from a social perspective (which he considers to be $c_{u}$, rather than $c_{u}-c_{\pi}$ ), which actually reinforces the two effects mentioned above in Proposition 3. Hence the condition mentioned in Proposition 3 remains sufficient (but even less necessary than in section 5) to obtain that $\theta_{u}^{M V}>\theta_{u}^{W}$.

\section{References}

[1] Acemoglu, D. (2003): "Patterns of skill premia", Review of Economic Studies, vol. 70, 2, pp. 199-230.

[2] Acemoglu, D. and Autor, D. (2011): "Skills, Tasks and Technologies: Implications for Employment and Earnings", in David Card and Orley Ashenfelter (eds.) Handbook of Labor Economics, vol. 4, part B, ch. 12, pp. 1043-1171.

[3] Allison, R.A. and J.E. Foster (2004): "Measuring health inequality using qualitative data", Journal of Health Economics 23 (2004) 505-524 
[4] Barberá, S. and Moreno, B. (2011): "Top monotonicity: A common root for single peakedness, single crossing and the median voter result", Games and Economic Behavior, vol. 73, 2, pp. 345-359.

[5] Blanden, J. and Machin S. (2004): "Educational Inequality and the Expansion of UK Higher Education", Scottish Journal of Political Economy, 51(2): 230-249.

[6] Bratti, M, Checchi, D and de Blasio, G .(2008): "Does the Expansion of Higher Education Increase the Equality of Educational Opportunities? Evidence from Italy." IZA DP No. 3361.

[7] Borck, R. and M. Wimbersky (2014): "Political Economics of Higher Education Finance", Oxford Economic Papers, 66(1), pp. 115-139.

[8] Carneiro, P. and Lee, S (2011): "Trends in Quality-Adjusted Skill Premia in the United States, 1960-2000", American Economic Review, vol. 101(6), pp. 2309-2349.

[9] Carnoy, M., Loyalka, P. and Androuschak, G. (2012): "Does Expanding Higher Education Equalize Income Distribution? The Case of the BRIC Countries", WP REAR, University of Stanford.

[10] Carnoy, M., Loyalka, P. and Dobryakova, M. (2013): University Expansion in a Changing Global Economy : Triumph of the BRICs? Stanford University Press.

[11] Chetty, R. (2006): "A New Method of Estimating Risk Aversion", American Economic Review, 96 (5), 1821-1836.

[12] De Fraja, G. (2001): "Education policies: Equity, efficiency and voting equilibrium", The Economic Journal, vol. 111, no. 471, pp. C104-C119.

[13] De Fraja, G. and Valbonesi, P. (2012): "The design of the university system", Journal of Public Economics, vol. 96, 3-4, pp. 317-330. 
[14] Del Rey, E. and Racionero, M. (2012): "Voting On Income-Contingent Loans For Higher Education," The Economic Record, The Economic Society of Australia, vol. 88(s1), pages 38-50, 06 .

[15] Del Rey, E. and Racionero, M. (2014): "Choosing the type of income-contingent loan: risk-sharing versus risk-pooling," Working Papers 2014/7, Institut d'Economia de Barcelona (IEB).

[16] Epple, D., and Romano, R. (1996): "Ends against the middle: Determining public service provision when there are private alternatives", Journal of Public Economics, vol. 62,3 , pp. 297-325.

[17] Epple, D., Romano, R. and Sieg, H. (2006): "Admission, tuition and financial aid policies in the market for higher education", Econometrica, vol. 74, 4, pp. 885-928.

[18] Eurydice (2013): National Tuition Fees and Support Systems. European Commission, Brussels.

[19] Fernández, R. and Rogerson, R. (1995): "On the political economy of education subsidies", Review of Economic Studies 62 (2): 249-262.

[20] Fu, C. (2014): "Equilibrium Tuition, Applications, Admissions and Enrollment in the College Market", Journal of Political Economy , 122(2): 225-281.

[21] Galindo-Rueda, F., Marcenaro-Gutierrez, O. and Vignoles, A. (2004): "The Widening Socio-Economic Gap in UK Higher Education", National Institute Economic Review, 190 (1): 75-88.

[22] Gans J. and M. Smart (1996): "Majority Voting with Single-crossing Preferences", Journal of Public Economics 59, 219-237.

[23] Garcia-Peñalosa, C. and Wälde (2000): "Efficiency and equity effects of subsidies to higher education", Oxford Economic Papers 52, pp. 702-722. 
[24] Gary-Bobo, R., and A. Trannoy (2008): "Efficient tuition fees and examinations", Journal of the European Economic Association 6, pp. 1211-1243.

[25] Haupt, A. (2012): "The evolution of public spending on higher education in a democracy", European Journal of Political Economy, Volume 28, Issue 4, pp. 557-573.

[26] OECD (2012): Education at a Glance 2012: OECD Indicators, OECD Publishing. http://dx.doi.org/10.1787/eag-2012-en

[27] OECD (2013): Education at a Glance 2013: OECD Indicators, OECD Publishing. http://dx.doi.org/10.1787/19991487

[28] Rahona-López, M. (2009): "Equality of opportunities in Spanish Higher Education", Higher Education 58: 285-306.

[29] Romano, R. and Tampieri, A. (2013): "Arts vs Engineering: The Choice among Consumption of and Investment in Education", Working Papers, Dipartimento Scienze Economiche, Universita' di Bologna.

[30] Sklar, A. (1959): "Fonctions de Répartition à n Dimensions et leurs Marges", Publications de l'Institut de Statistique de l'Université de Paris, 8, 229-231.

[31] Vona, F. (2012): "Does the Expansion of Higher Education Reduce Educational Inequality? Evidence from 12 European Countries", Documents de Travail de l'OFCE from Observatoire Francais des Conjonctures Economiques (OFCE), no. 2011-12. 


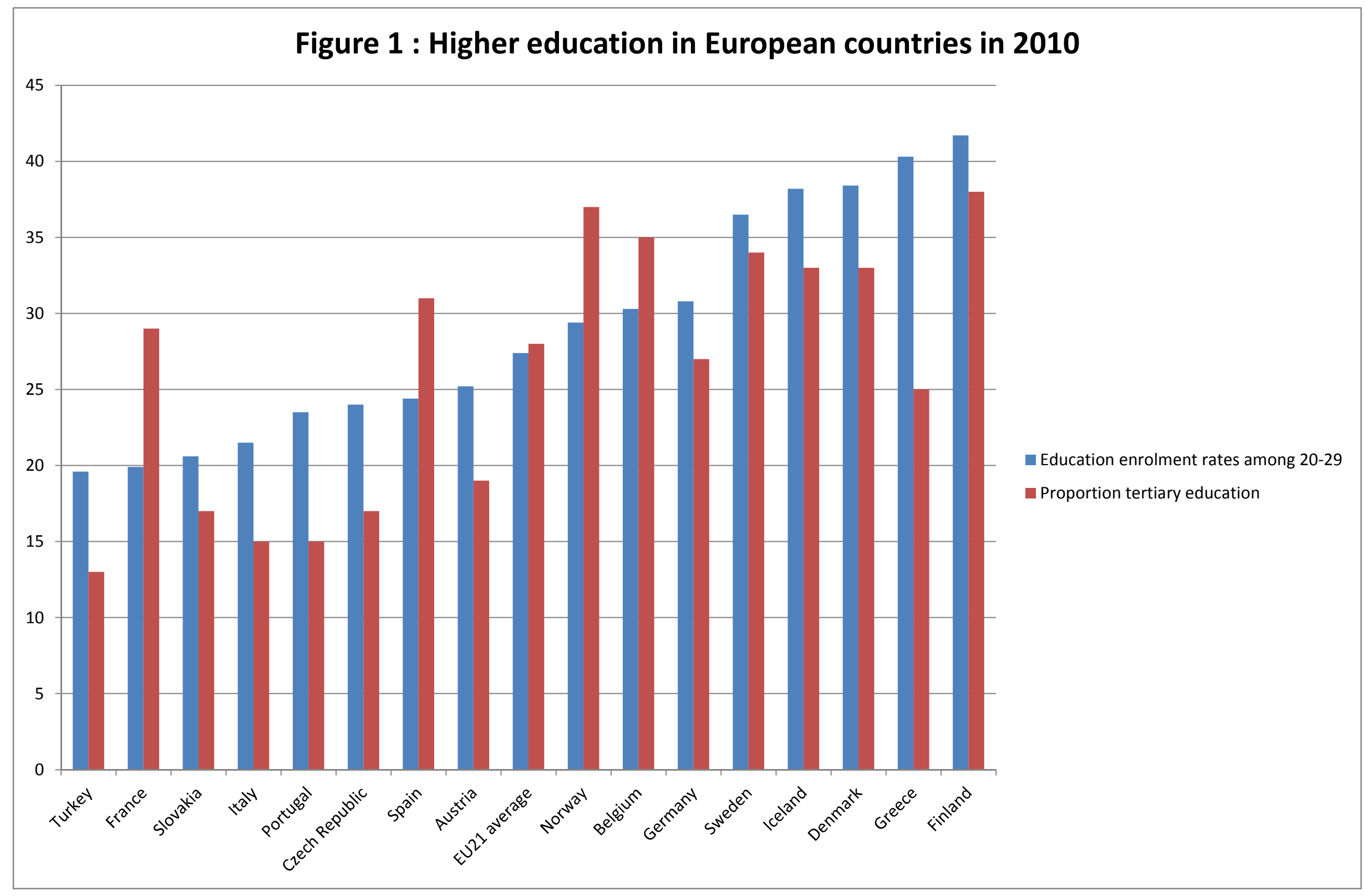




\section{Figure 2: Single-Peaked Preferences}

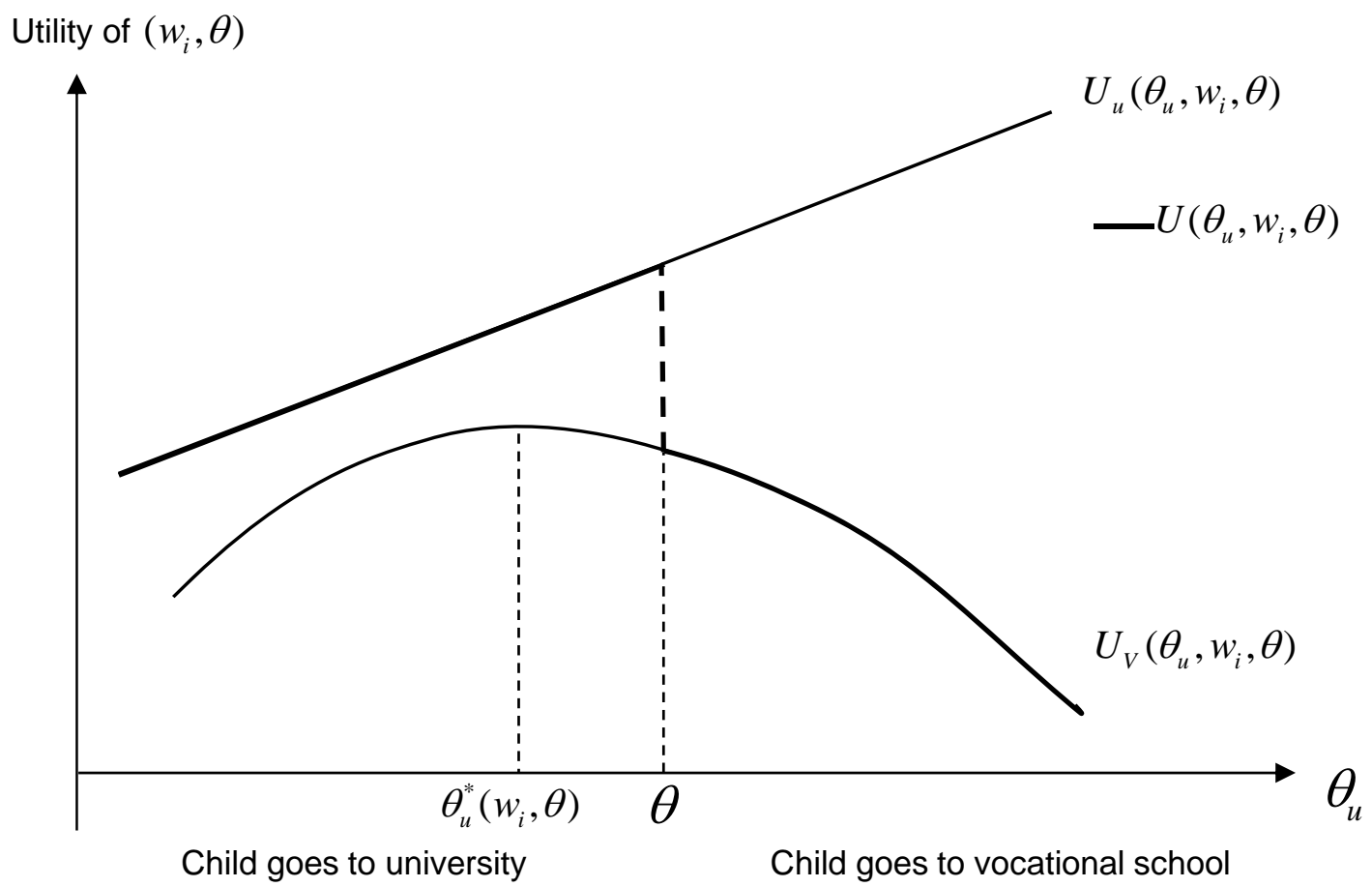

Figure 3 : Non Single-Peaked Preferences

Utility of $\left(w_{i}, \theta\right)$

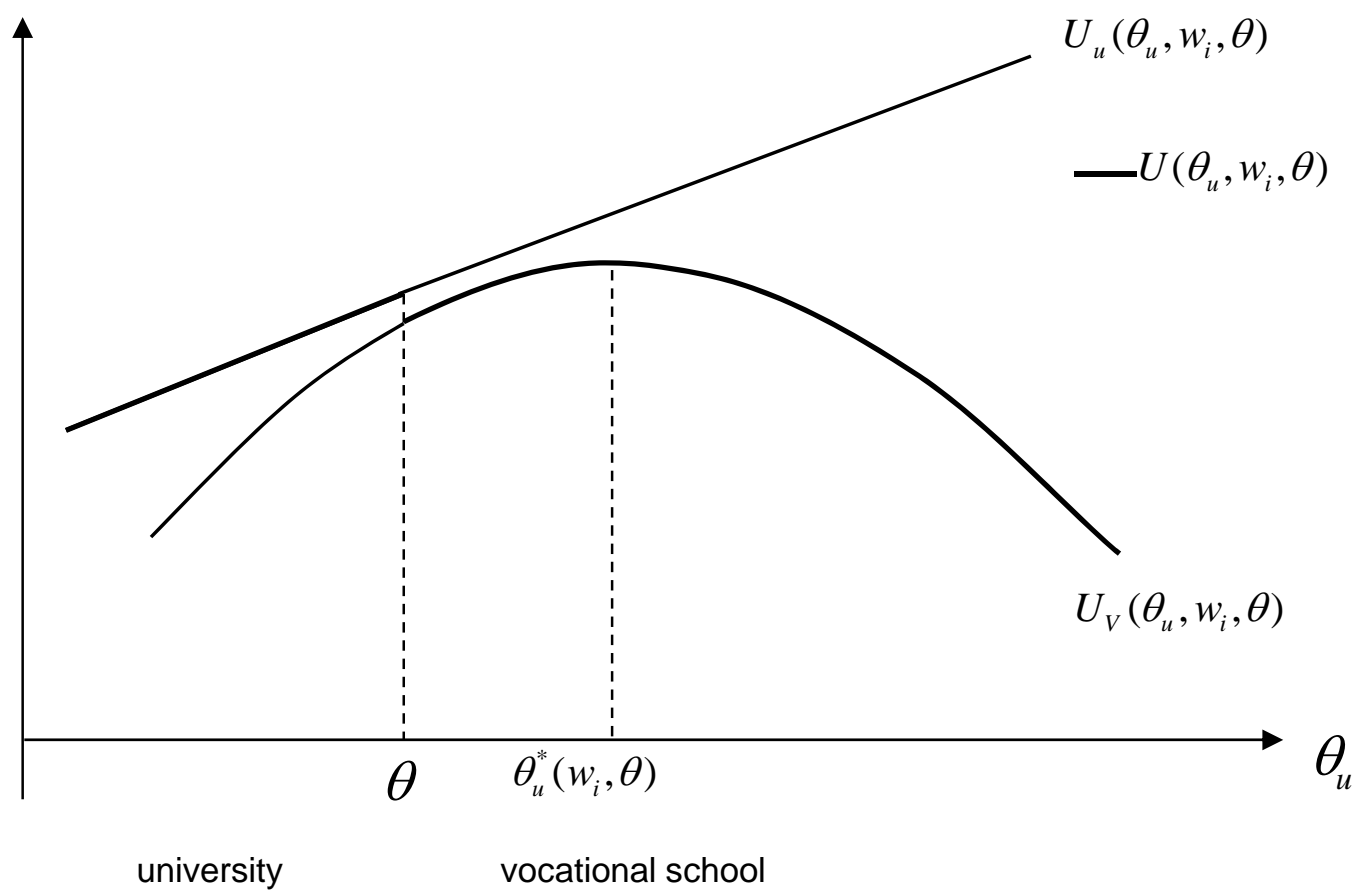


Most-preferred $\theta_{u}$

Figure 4 : Classical Equilibrium of $\left(w_{i}, \theta\right)$

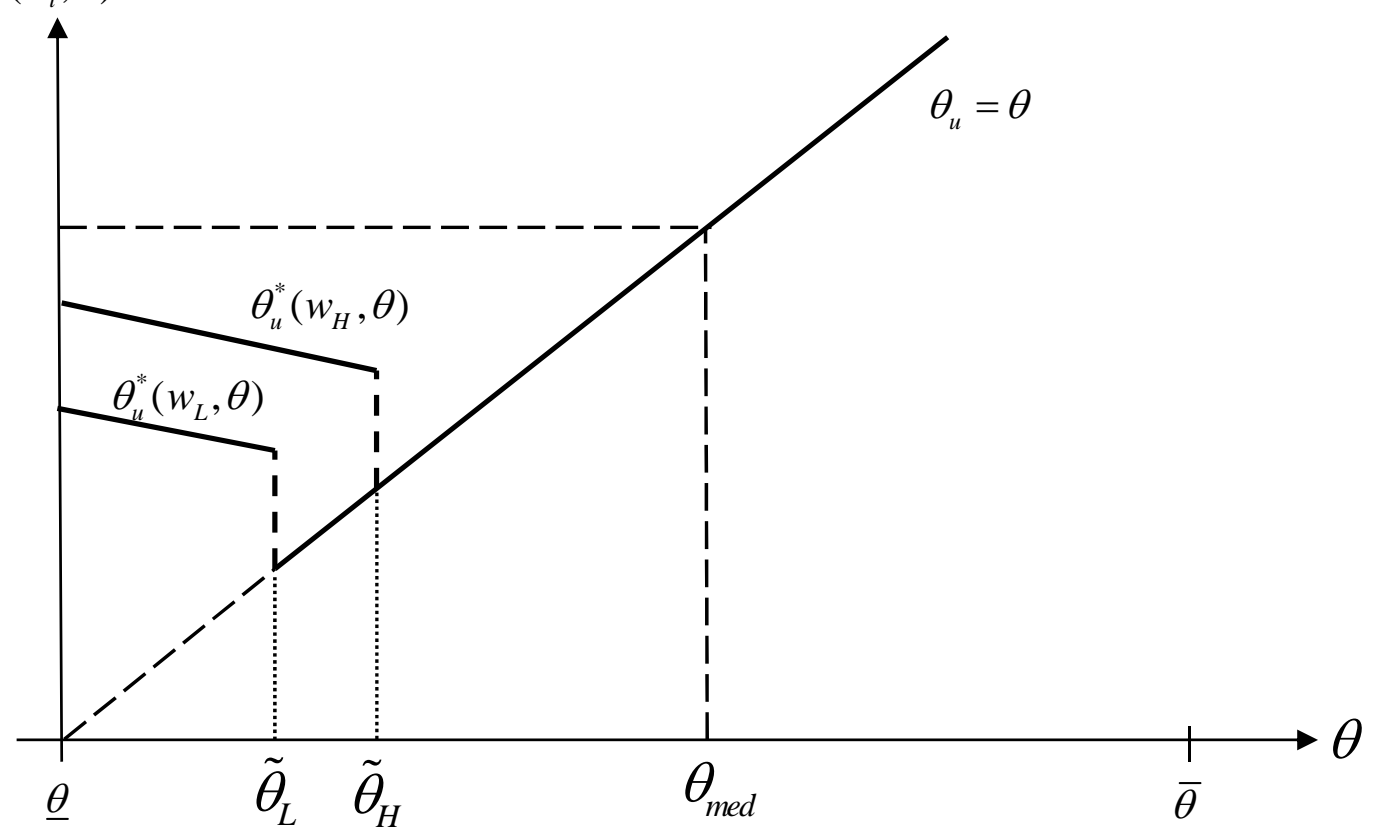

Figure 5 : Ends-against-the-middle equilibrium

Most-preferred $\theta_{u}$

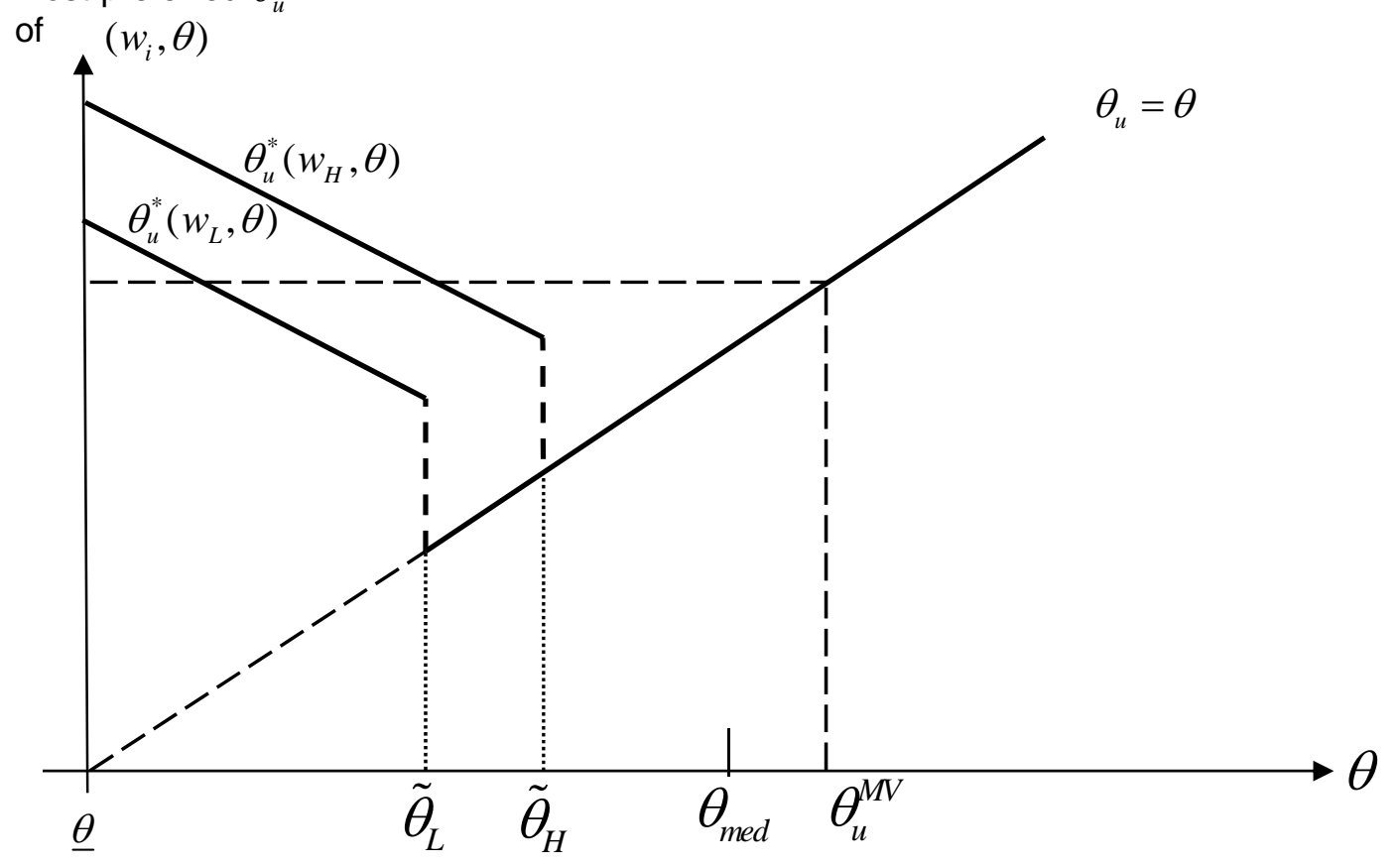


Figure 6 : Most - preferred university size with no correlation between income and skill

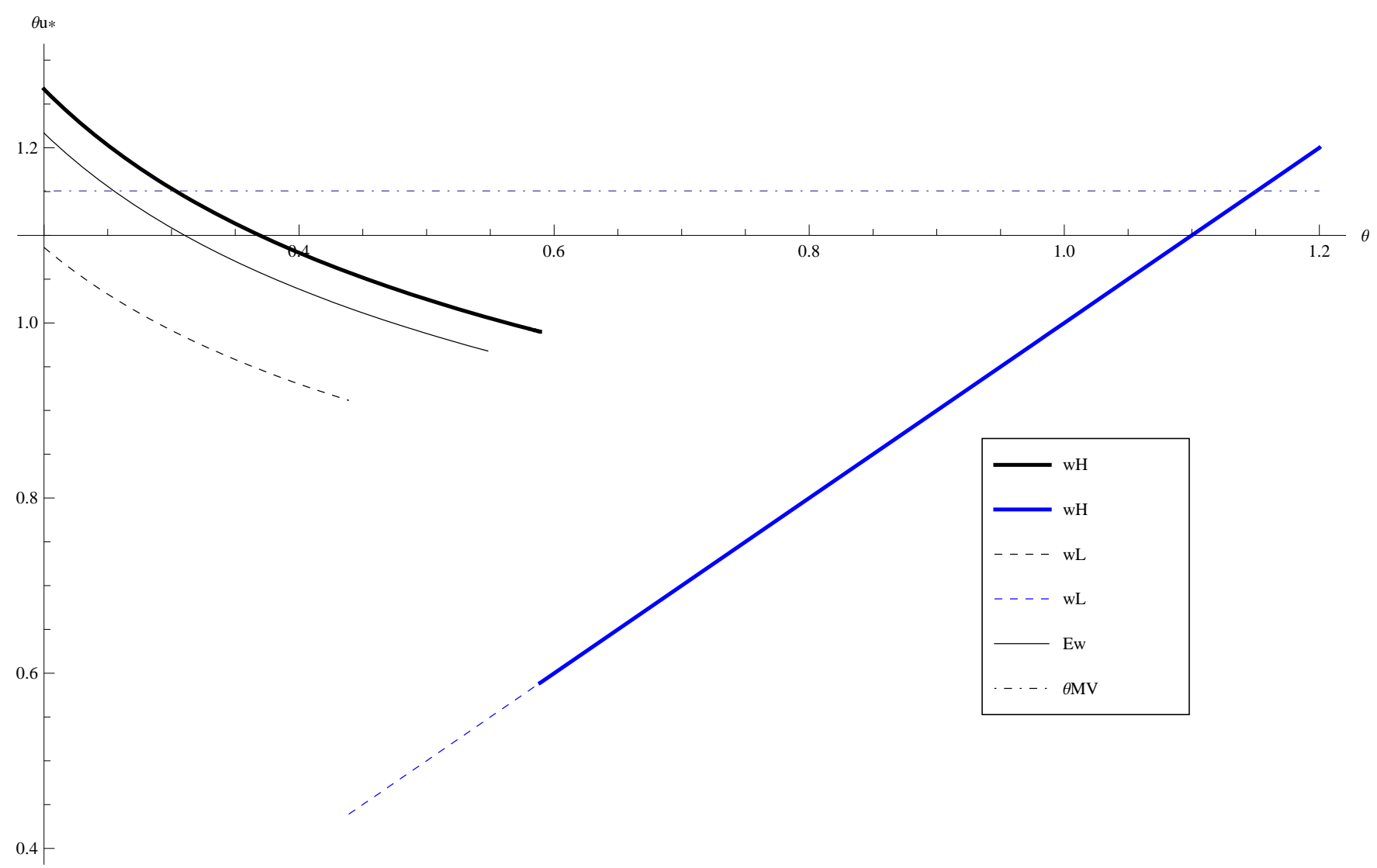


$\mathbf{2}$ | Figures with numerical simulations.nb

Figure 7 : Coalitions in the end - agaisnt - the - middle equilibrium with no correlation

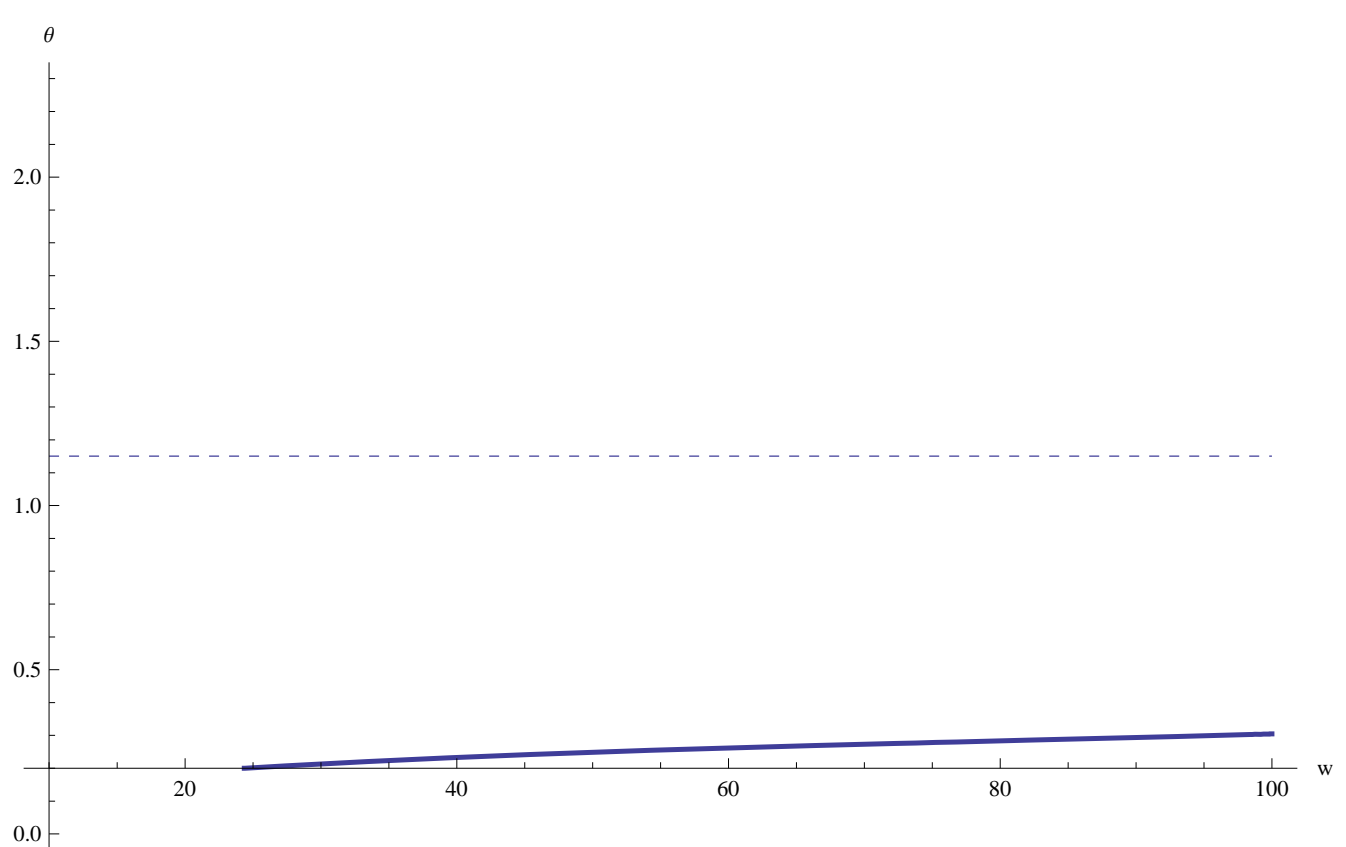


Figure 8 : The equilibrium size of the university as a function of the correlation between income and skill Equilibrium fraction of university

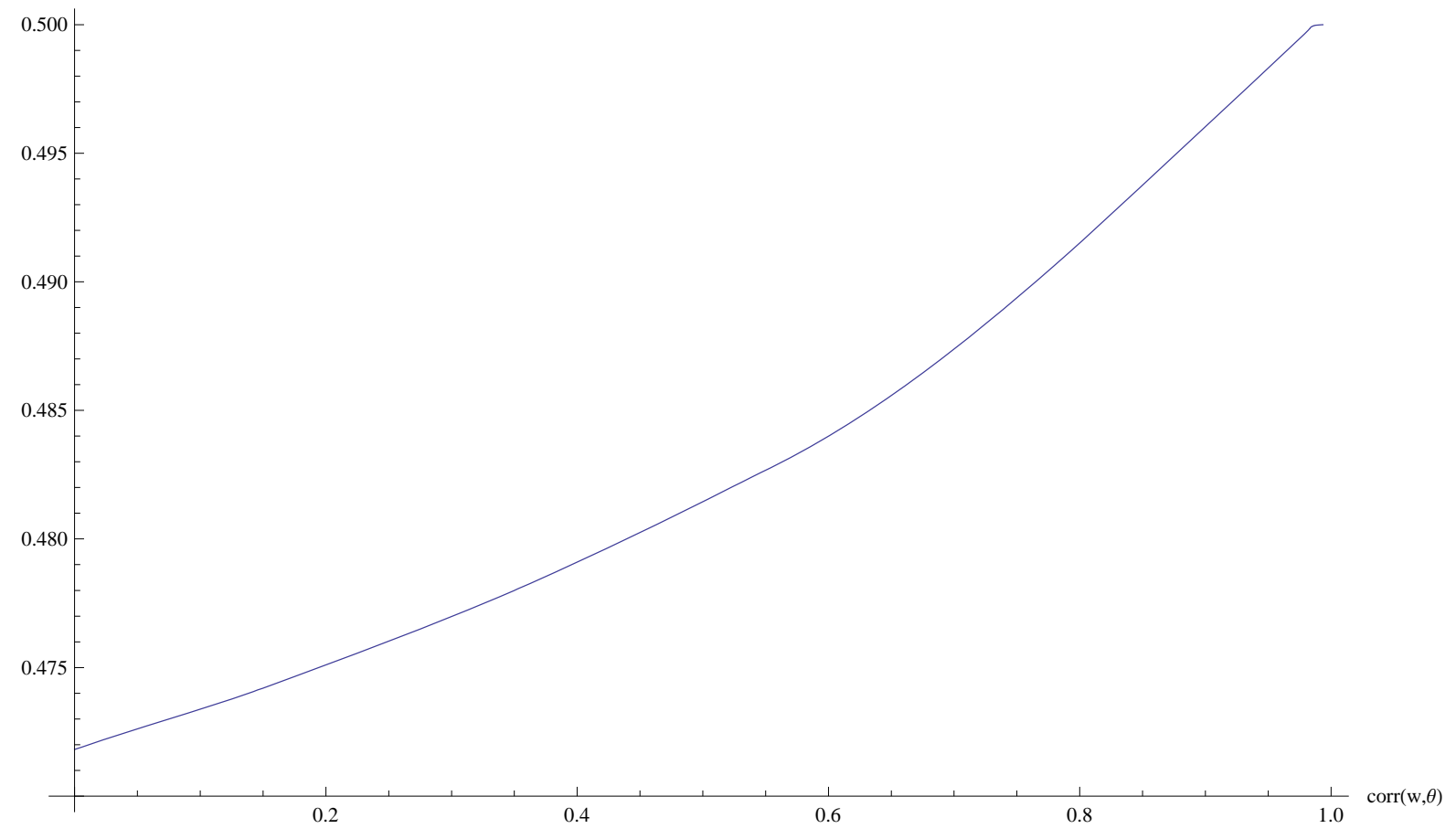


4 Figures with numerical simulations.nb

Figure 9 : The impact of the correlation between income and skill on the composition of the universities ' s student body

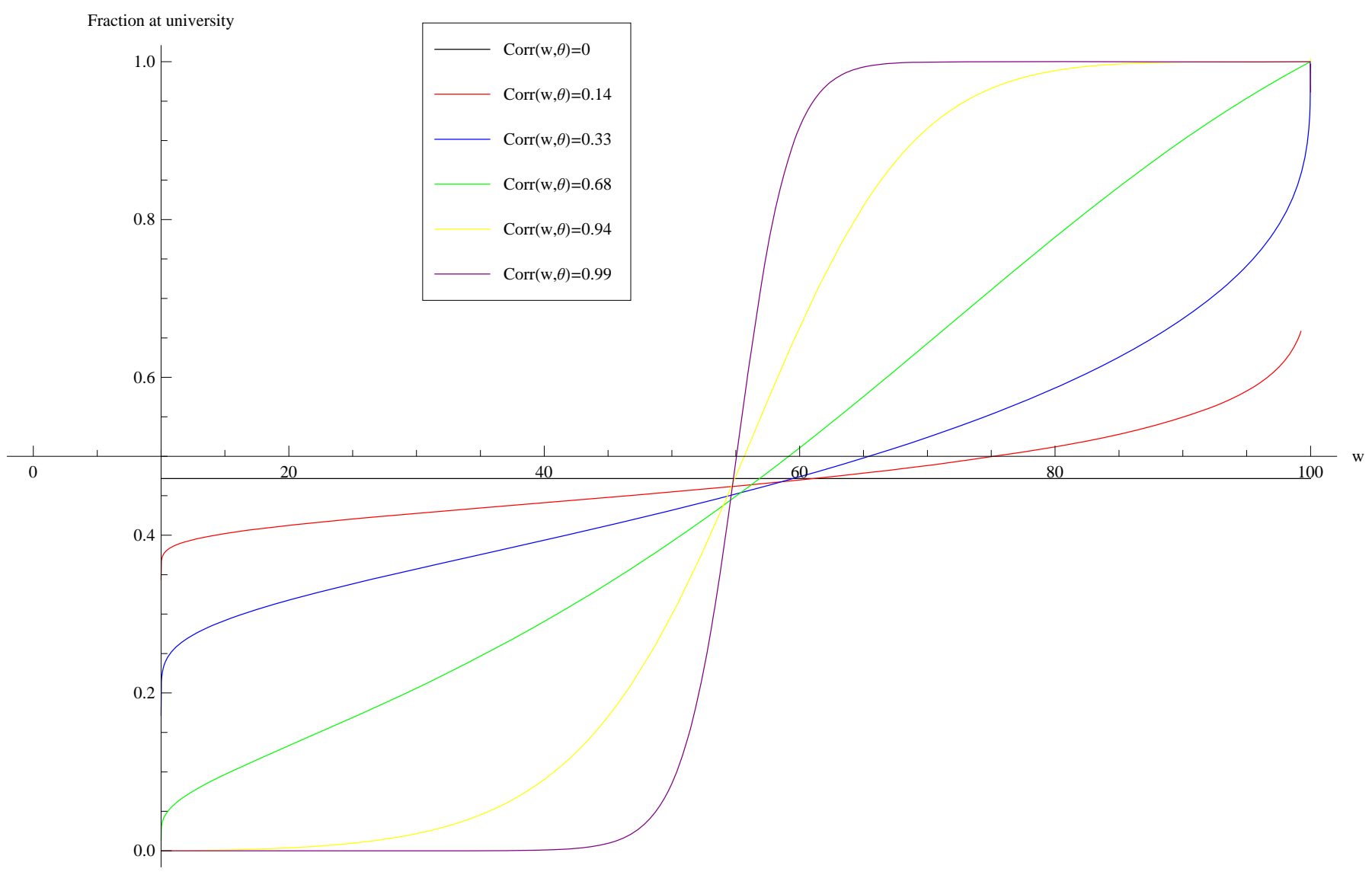


Most-preferred $\theta_{u}$

Figure $10 \mathrm{a}$ : Assumption 1 not satisfied

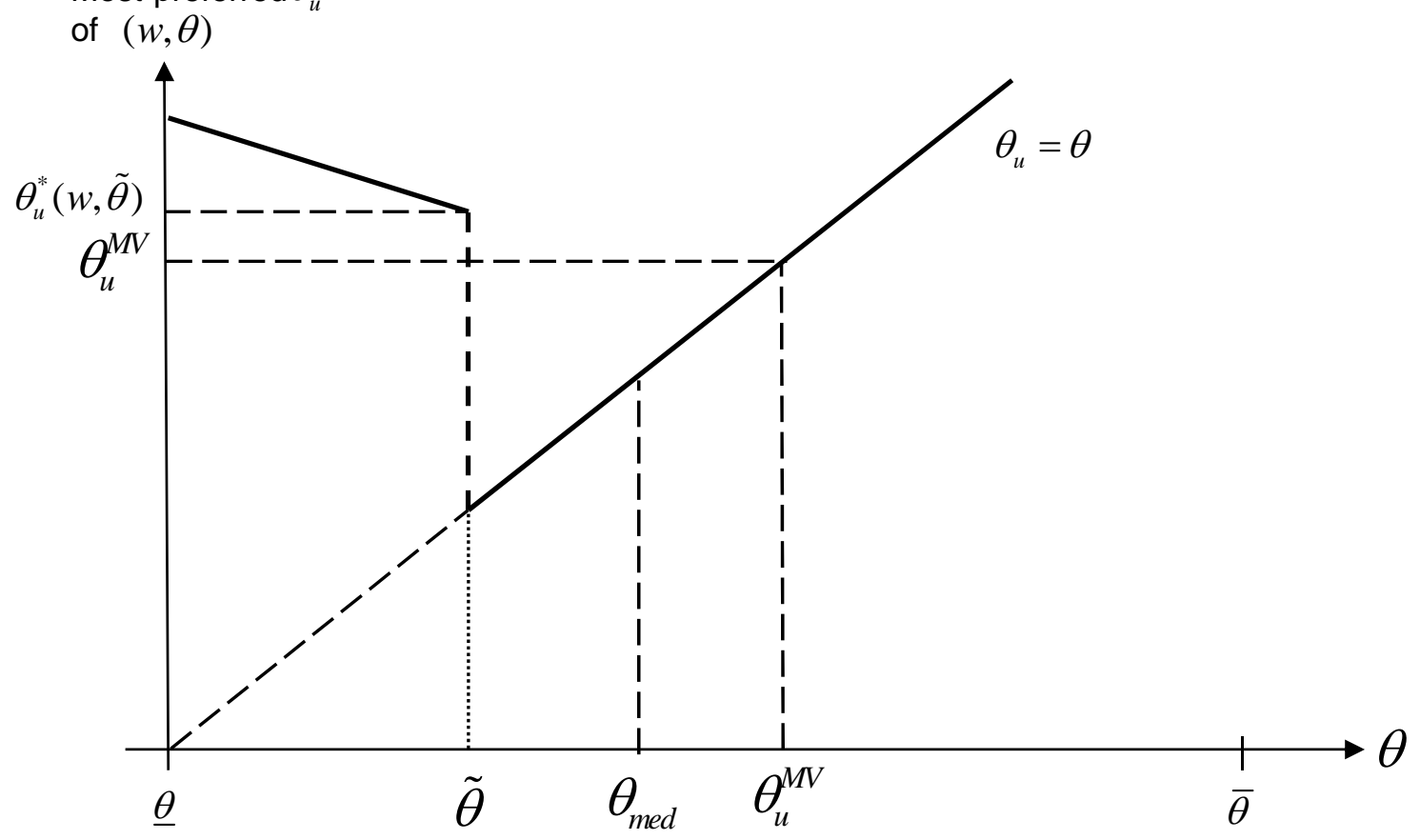

Figure $10 \mathrm{~b}$ : Non single-peaked preferences

Utility of $(w, \tilde{\theta})$

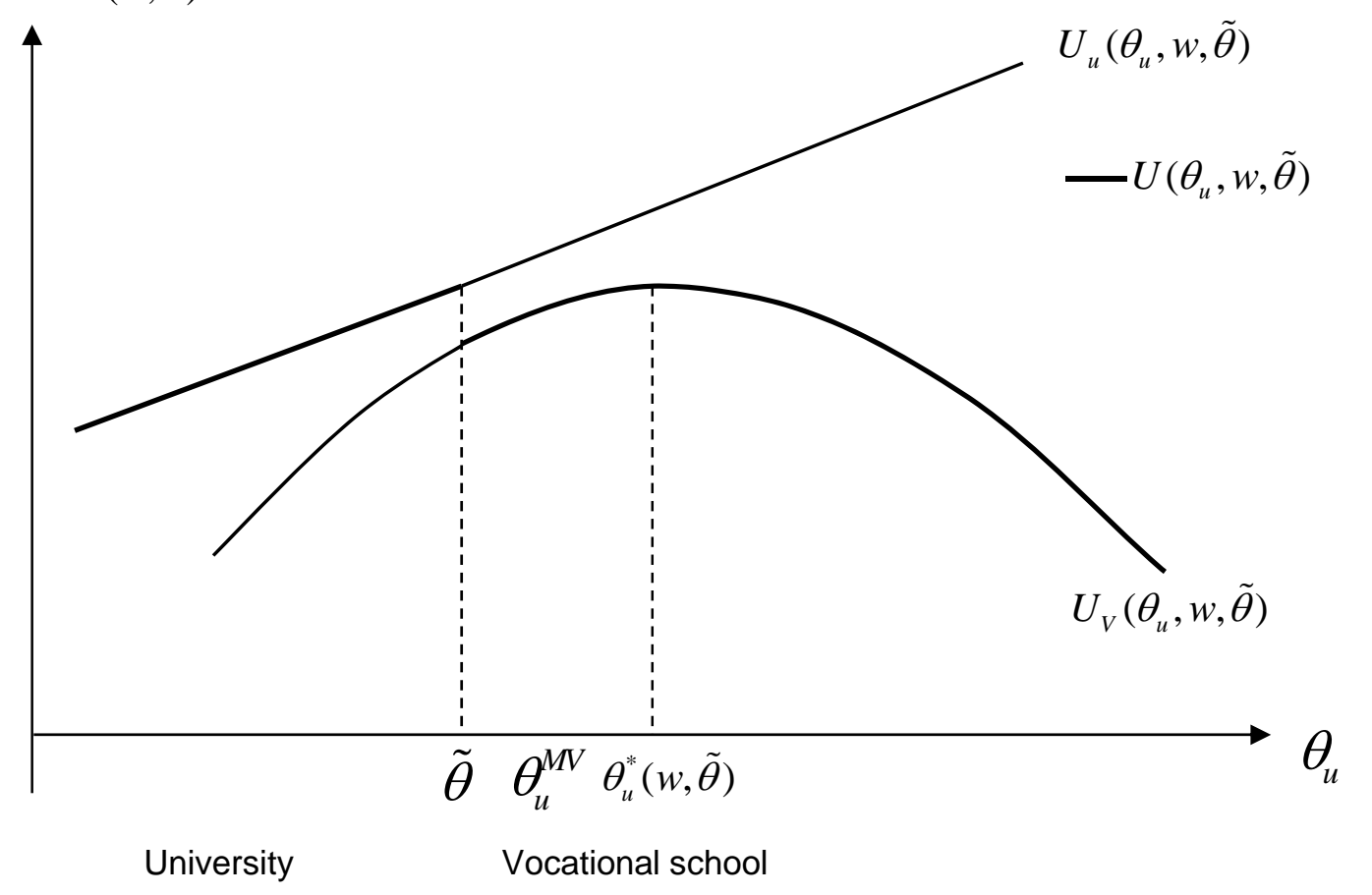

